\title{
Fundamentals of the coupled thermo-hydro-mechanical behaviour of thermo-active retaining walls
}

\author{
Eleonora Sailer, MEng MSc DIC, Postgraduate Researcher \\ David M.G. Taborda, MEng PhD DIC, Senior Lecturer
}

Lidija Zdravković, MEng MSc PhD DIC, Professor of Computational Geomechanics

David M. Potts, BSc PhD DSc, FREng FIC, FCGI, GCG Professor of Geotechnical Engineering

Department of Civil and Environmental Engineering, Imperial College London, UK

\author{
Corresponding author: \\ Eleonora Sailer
}

Skempton Building, Imperial College London, South Kensington Campus, London, SW7 2AZ

$+44(0) 2075946060$

eleonora.sailer13@imperial.ac.uk 


\begin{abstract}
Geotechnical structures can be employed to provide renewable and cost-effective thermal energy to buildings. To date, limited field studies regarding thermo-active retaining walls exist and therefore their mechanical response under non-isothermal conditions requires further research to comprehend their behaviour. This paper investigates the response of a hypothetical thermo-active diaphragm wall by performing finite element analysis to characterise in detail its short and long term response. The soil-structure interaction mechanisms arising from the coupled thermo-hydro-mechanical nature of soil behaviour are for the first time identified and shown to be complex and highly non-linear. Subsequently, simpler modelling approaches are used to isolate and quantify the impact of the various identified mechanisms on the design of thermo-active retaining walls. It is concluded that simpler approaches tend to overestimate structural forces developing due to temperature changes in the retaining wall, while severely underestimating the associated ground movements, which are highly influenced by the development of thermally-induced excess pore water pressures. Furthermore, the results suggest that the behaviour of thermo-active retaining walls is highly transient in nature, as a result of the high rates of heat transfer and pore water pressure dissipation under plane strain assumptions.
\end{abstract}

Keywords: thermo-active retaining walls, numerical analysis, thermo-hydro-mechanical coupling 
The constant increase in energy demand, as well as stricter sustainability targets, have led in the past decades to the development of new strategies for energy exploitation from natural resources. One of these is based on the extraction of heat from the ground at shallow depths (up to $300 \mathrm{~m}$ ) through the installation of ground source energy systems (GSES) (Banks, 2012). One type of GSES employs closed loops, where the exchange of heat with the ground is carried out by circulating a fluid through pipes that are either installed directly in the ground or within buried structures.

The installation of closed loops within geotechnical structures, such as foundation piles, tunnels and retaining walls, dates back to the 1980s (Adam and Markiewicz, 2009), and is an efficient and economically sustainable solution involving structures which are able to provide both stability and energy to buildings. However, any exchange of heat will necessarily result in changes in temperature of the thermo-active structure and surrounding soil, inducing additional loads within the structures as well as changes to the mechanical and hydraulic conditions within the soil mass. Given the many uncertainties and concerns regarding the safe use of geotechnical structures, numerous field and numerical studies have been carried out in the last decade, the focus of these mainly involving thermoactive piles. For this type of structure, a simplified framework for understanding their behaviour when subjected to thermal loads has been developed based on field observations (Bourne-Webb et al. 2009; Amatya et al. 2012; Bourne-Webb et al. 2013). Conversely, retaining walls have been the subject of limited studies and many uncertainties regarding the safe design and operation of these structures exist, as they behave in a very different manner from piles given their more complex geometry and boundary conditions. Brandl (2006) reported wall movements of a thermo-active contiguous bored pile wall installed as part of a cut and cover tunnel of the Vienna Metro in Austria. Initial results indicated that the thermal effects on the movements of the wall are negligible. However, the monitoring comprised only seven months of heat pump operation and therefore the long-term performance is not known. Two further field tests were undertaken (Xia et al., 2012; Sterpi et al., 2018), but the focus of these studies was the thermal performance (i.e. temperature measurements) of diaphragm wall panels, meaning that no strain measurements in the panels were included in the monitoring scheme. In terms of numerical studies, Finite Element (FE) analyses have been employed to investigate the thermo-mechanical behaviour of thermo-active walls. These include a fully coupled thermo-hydro-mechanical (THM) simulation of a thermo-active diaphragm wall installed at the Tottenham Court Road Station in London, UK (Soga et al., 2014; Rui and Yin, 2017). They concluded that the applied (hypothetical) heating/cooling cycles do not greatly affect the structural forces in the long term, which remain within the design envelope. However, they observed that changes in temperature delay the dissipation of excess pore water pressures due to construction and induce a permanent deformation of the soil mass. Bourne-Webb et al. (2015) and Bourne-Webb et al. (2016) investigated the behaviour of a wall forming part of a cut and cover tunnel through a 2D plane strain thermo-mechanical finite element analysis, hence no hydraulic coupling was involved. The influence of the soil's coefficient of thermal expansion and the boundary condition at the exposed face of the wall on horizontal wall movements and bending moments was analysed. The results suggest that the boundary conditions on the exposed face of the wall, such as air flow and temperature fluctuations (which would also be present if the wall was not thermo-active) seem to affect the mechanical response of the wall to a larger extent than the thermal load induced by exchanging heat with the surrounding ground. Sterpi et al. (2017) performed both 2D and 3D thermo-mechanical FE analysis of a basement wall installed within granular material (i.e. no generation of pore water pressures). In contrast to previous studies, the authors indicated that changes in temperature may significantly affect the forces within a retaining wall. They also observed, in agreement with other studies (Bourne- 
Webb et al., 2016; Rui and Yin, 2017), that wall movements and earth pressures are not greatly influenced by the exchange of heat.

Given the limited number of studies concerning the behaviour of thermo-active retaining walls, especially with regard to the thermo-hydro-mechanical effects on the soil-structure interaction, it is clear that further research is required to fully comprehend the complex nature of such a problem. In this paper, fully coupled THM FE analyses are performed to characterise the non-isothermal response of a hypothetical thermo-active diaphragm wall located in central London. The focus of this study is to outline how different approaches to the modelling of this type of thermo-active structures can influence their design. Furthermore, it aims to give clear insights into the fundamental soil-structure interaction mechanisms inducing changes in the behaviour of such walls in terms of pore water pressures, structural forces and wall and ground movements in the short and long term.

The first part of this paper simulates the excavation sequence of a deep basement in London (Wood \& Perrin, 1984a; Wood \& Perrin, 1984b), for which detailed field data is available, with the aim of validating the employed mechanical and hydraulic soil models and properties. Subsequently, different FE analyses based on the same geometry of the analysed case study, hypothesising the use of the wall as a heat exchanger, are presented. The finite element analyses presented in this paper are carried out using the Imperial College Finite Element Code (ICFEP, Potts and Zdravković, 1999), which is capable of performing fully coupled THM simulations. The THM finite element formulation and the thermal boundary conditions are described in Cui (2015), Cui et al. (2016a) and Cui et al. (2018).

In this paper, the adopted sign convention dictates that positive values refer to tensile axial forces in the wall, bending moments as a result of tension on the excavated side of the wall, upwards vertical movements, horizontal movements towards the retained soil, tensile strains, and compressive pore water pressures.

\section{Validation of the hydro-mechanical model: a case study in central London}

This section provides the description and numerical results of a deep excavation in London, with the purpose of validating the hydro-mechanical model

\subsection{Problem description}

The analysed case study is presented in Wood \& Perrin (1984a) and Wood \& Perrin (1984b): an $11 \mathrm{~m}$ deep excavation for an underground car park, $100 \mathrm{~m} \times 60 \mathrm{~m}$ in plan, of a six storey building located in central London is supported by an $18 \mathrm{~m}$ deep, $800 \mathrm{~mm}$ thick diaphragm wall (Figure 1). During excavation, the wall was supported by a propping system consisting of a steel frame supported by concrete soldier piles. As shown in Figure 1, three temporary prop levels were installed and the struts were pre-stressed in the field, with design values of $50 \mathrm{kN} / \mathrm{m}, 80 \mathrm{kN} / \mathrm{m}$ and $120 \mathrm{kN} / \mathrm{m}$ for prop levels 1,2 and 3, respectively. Each of the temporary props were removed after construction of the permanent structures, i.e. the concrete base slab $(1.5 \mathrm{~m}$ thick) and the three slab levels $(350 \mathrm{~mm}$ thick), as indicated in the construction sequence outlined in Table 1. In order to limit the impact of modelling simplifications (Zdravković et al., 2005), 2D plane strain analyses were carried out on a section perpendicular to the walls of greatest length (east and west walls), as this type of analyses is typically employed to simulate structures of large dimension in the out-of-plane direction (Potts \& Zdravković, 1999). 


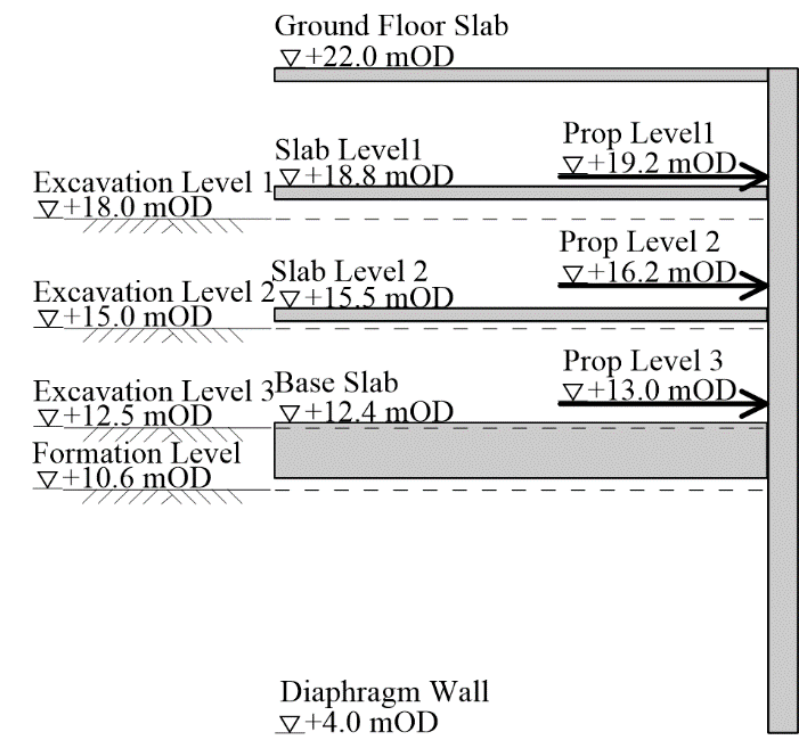

Figure 1: Cross-section of diaphragm wall and construction levels

The ground profile was determined from the site investigation information reported in Wood \& Perrin (1984a) and from available borehole data nearby the site. These indicated the level of ground surface to be at $+22.0 \mathrm{mOD}$ and a ground profile consisting of $4.8 \mathrm{~m}$ of Made Ground (MG), $2.0 \mathrm{~m}$ of Terrace Gravel Deposits (TGD), $40.0 \mathrm{~m}$ of London Clay (LC), $12.0 \mathrm{~m}$ of Lambeth Group Clay (LGC) and $7.0 \mathrm{~m}$ of Thanet Sand (TS) overlying Chalk (CH), as displayed in Figure 2. The groundwater table was located at $4.0 \mathrm{~m}$ below ground level, i.e. at $18.0 \mathrm{mOD}$, and the pore water pressure was assumed to be $0.0 \mathrm{kPa}$ above that datum. For the initial conditions prior to excavation, the pore water pressure was assumed to vary hydrostatically within the Made ground, the Terrace Gravel Deposits and the Thanet Sand. Moreover, according to the Environment Agency's records (Environment Agency, 2016), the water table for the lower aquifer at the time of construction (early 1980) was estimated to be located at the top of the Thanet Sand layer. Within the London Clay and Lambeth Group Clay, the pore water pressure profile was assumed to be underdrained, in equilibrium with the hydraulic boundary conditions described above and consistent with the permeability profile (obtained from Equation 1 in section 2.2.2), as shown in Figure 2 (a). The adopted $K_{0}$ profile is similar to that described in Gawecka et al. (2017) and is displayed in Figure 2 (b). This is based on the profile provided by Schroeder et al. (2004) which has been established according to the field data presented in Hight et al. (1993). 


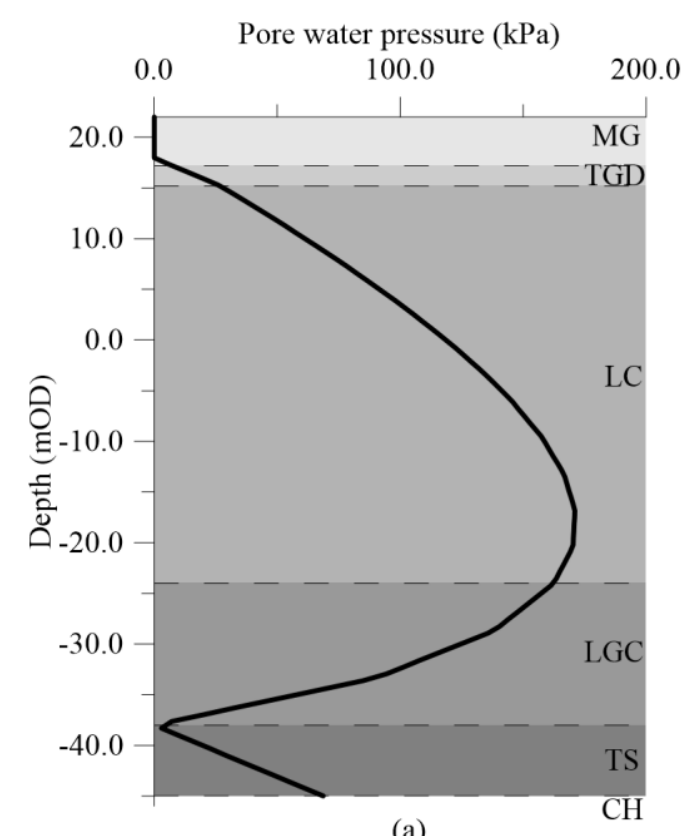

(a)

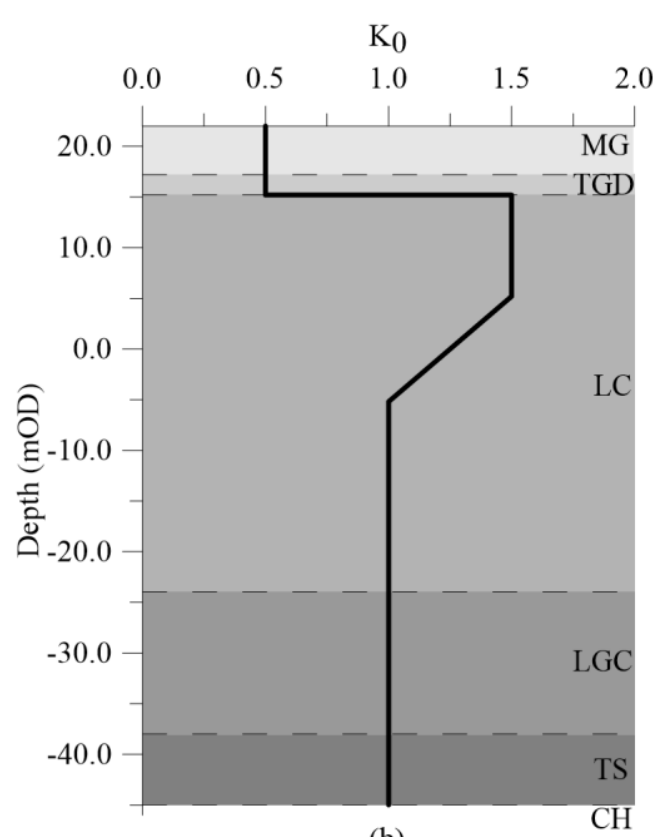

(b)

Figure 2: Initial ground conditions (a) pore water pressure and (b) Ko profile

\section{$2.2 \quad$ Numerical analysis}

\subsubsection{Finite element model}

Figure 3 shows the FE mesh with an indication of its dimensions and the position of structural components. A symmetric excavation was assumed, hence only half $(30 \mathrm{~m})$ of the full excavation width $(60 \mathrm{~m})$ was modelled. Furthermore, no indication of the arrangement of internal columns was provided in the reference paper, which were therefore assumed to be $0.25 \mathrm{~m}$ wide and spaced $6.0 \mathrm{~m}$ apart. Eight-noded quadrilateral solid finite elements were used to model all soils, with displacement and temperature degrees of freedom at all the nodes and with pore water pressure degrees of freedom added to the corner nodes of the finite elements discretising consolidating materials (i.e. London Clay and Lambeth Group Clay). Cui et al. (2016b) describe in detail the performance in THM analyses of these hybrid finite elements. The structural components were simulated using eight-noded solid finite elements with displacement degrees of freedom at all the nodes. The connection between the diaphragm wall and the internal structures was simulated as a pin connection, i.e. only axial and shear forces can be transferred. 


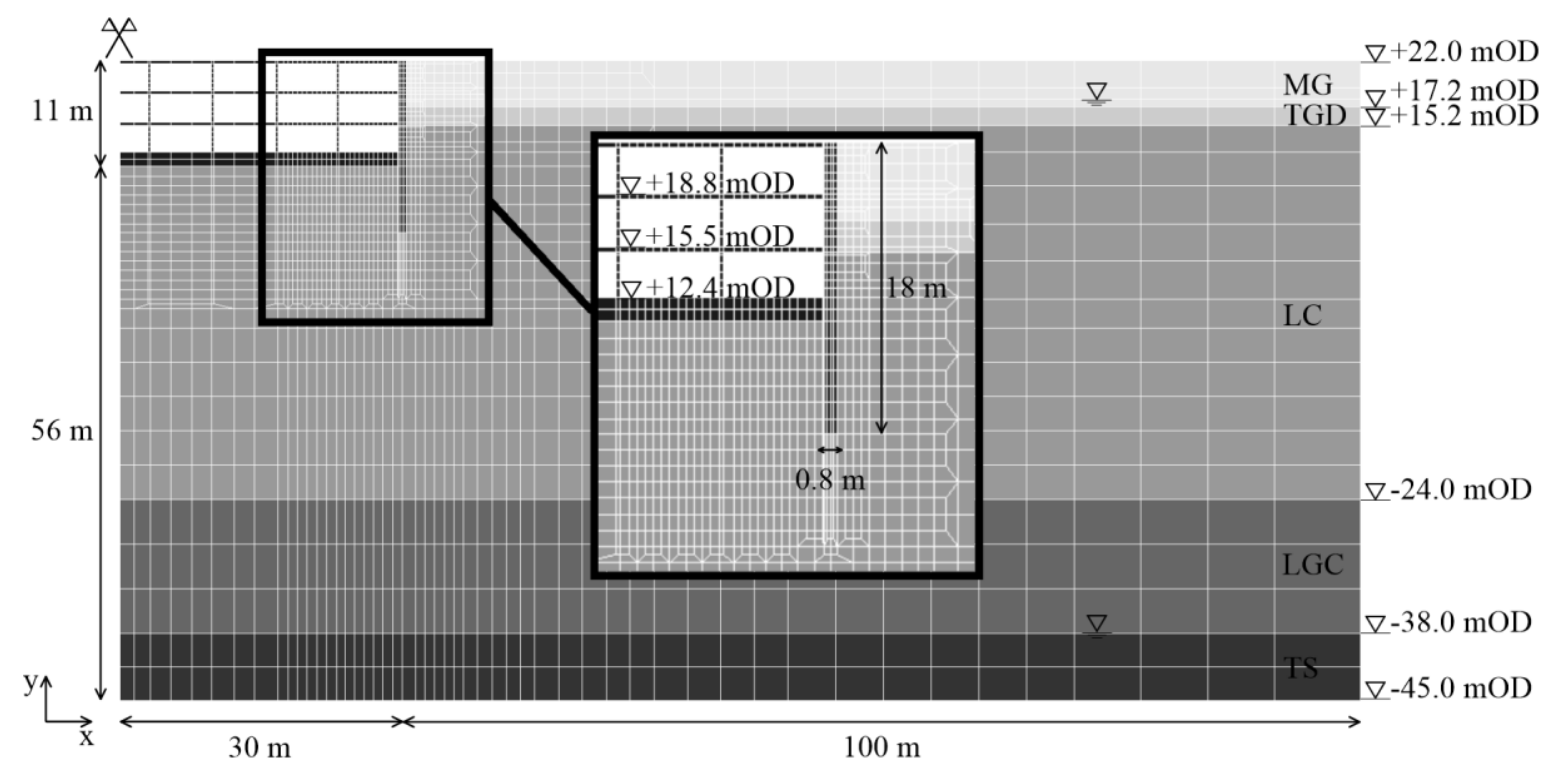

Figure 3: FE Mesh

\subsubsection{Material properties}

Concrete was modelled as a linear-elastic material with a stiffness of $30 \mathrm{GPa}$, as indicated in Wood \& Perrin (1984a). Excluding the Made Ground, which was modelled as a linear elasto-plastic material with a Mohr-Coulomb failure surface, all other soil layers were modelled as non-linear elasto-plastic materials, coupling a Mohr-Coulomb failure surface with the IC.G3S non-linear elastic stiffness model (Taborda et al., 2016). The latter allows the simulation of the non-linear decay of the soil's stiffness with strain level within the elastic region, improving the predictions of the pre-yield soil response. The model's equations can be found in Appendix A. All mechanical and hydraulic soil properties were adopted from Gawecka et al. (2017), with the former properties being listed in Appendix A. For consolidating materials, i.e. London Clay and Lambeth Group Clay, a non-linear permeability model was adopted, where the permeability decreases with increasing mean effective stress, $p^{\prime}$, according to the following relationship:

$$
k=k_{0} e^{-B p \prime}
$$

where the parameters $k_{0}$ and $B$ are model parameters and where taken respectively to be equal to $1.0 \times 10^{-10} \mathrm{~m} / \mathrm{s}$ and 0.0023 according to Schroeder et al. (2004).

\subsubsection{Modelling procedure}

A plane strain fully coupled Hydro-Mechanical (HM) analysis was carried out to simulate the excavation and construction of the permanent structures as shown in Figure 3 and according to the construction sequence outlined in Table 1 . The domain was restrained in the vertical direction along the bottom boundary and in the horizontal direction along the lateral and bottom boundaries. In terms of hydraulic boundary conditions, no water flow was allowed across the lateral boundaries, while the Made Ground, the Terrace Gravels and Thanet Sand were considered to be free-draining materials (imposing therefore no change in pore water pressures at the top of the London Clay layer and the bottom of the Lambeth Group Clay layer). Each of the temporary struts were simulated as a spring acting at a node with an assumed stiffness of $50 \mathrm{MN} / \mathrm{m}^{2}$. The pre-stress of the struts was simulated by applying a nodal force equal to the design pre-stress value indicated in Wood \& Perrin (1984a).

The wall was "wished in place" (i.e. the wall construction is not simulated and installation effects are neglected) and full friction was assumed at the soil-wall interface. Given the consolidating nature of the clayey materials, the excavation and construction events have been simulated by reproducing the actual times required according to the construction sequence outlined in Wood \& Perrin (1984a), 
whereas the installation of the temporary struts was simulated as an instantaneous event. Moreover, at the start of the construction of the internal structure, the soils' stiffness was reset as a consequence of the associated reversal in loading direction (Gawecka et al. 2017; Schroeder et al. 2004).

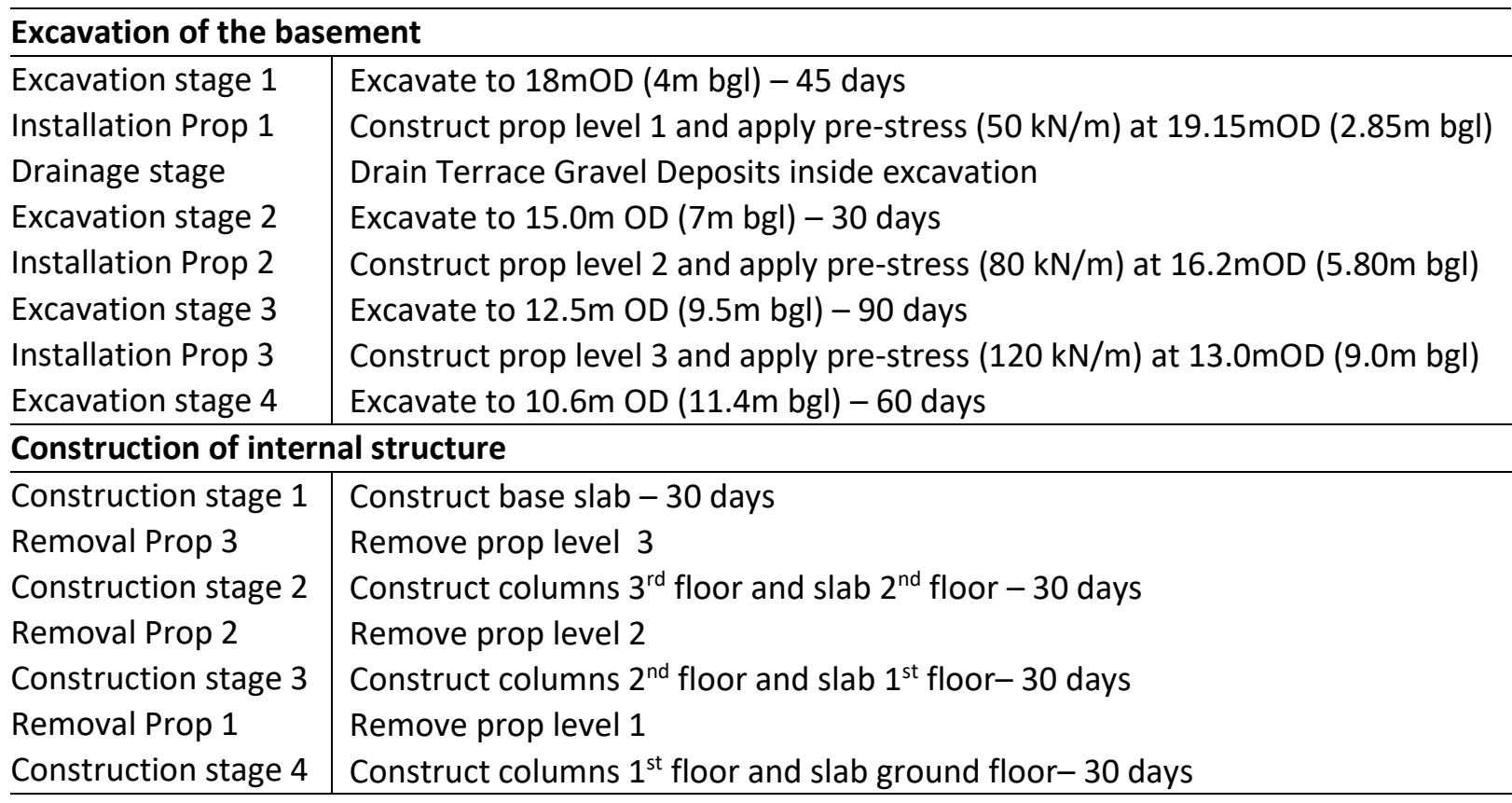

Note: bgl - below ground level

Table 1: Analysis sequence

\subsection{Comparison of measured and simulated results}

The results of the numerical analysis in terms of horizontal wall movements are compared to the monitoring data from inclinometers labelled as "i1", "i3", " $i 4$ " and "i7" in Wood \& Perrin (1984a). The horizontal displaced shapes at different construction stages are displayed in Figure 4.

In general, the predictions of the FE analysis agree well with the measured data. The wall response is especially well simulated during the first two excavation stages and during construction of the permanent floors and columns, whereas a larger wall deflection is predicted by the numerical analysis at about $10 \mathrm{~m}$ depth during the last two excavation stages. These discrepancies, while important, are deemed to be acceptable, particularly when considering that, apart from the stratigraphy, limited sitespecific data were available regarding the behaviour of the materials or the initial $\mathrm{K}_{0}$ profile. Furthermore, the temporary support system consisted of a complex steel frame, the modelling of which under plane strain assumptions is inherently approximate. In addition, no characterisation of its stiffness had been provided in the literature, meaning that a nominal value had to be assumed ( 50 $\left.\mathrm{MN} / \mathrm{m}^{2}\right)$.

Clearly, the good agreement between the numerical and measured responses provides confidence in the ability of the numerical model (including initial conditions, finite element discretisation, hydraulic and mechanical parameters and boundary conditions) to simulate accurately the complex soilstructure interaction phenomena associated with the construction of this retaining structure. As a result, it is expected that this validation exercise contributes to the reduction in the uncertainty associated with the modelling of this wall under hypothetical thermal loads. Clearly, a comparison with field data characterising the thermo-mechanical behaviour of a thermo-active wall would have provided a better illustration of the performance of the modelling approach presented in this paper. 
However, a complete dataset including details of both the thermo-active structure and the behaviour of the surrounding soil is currently unavailable, rendering such an exercise impossible.

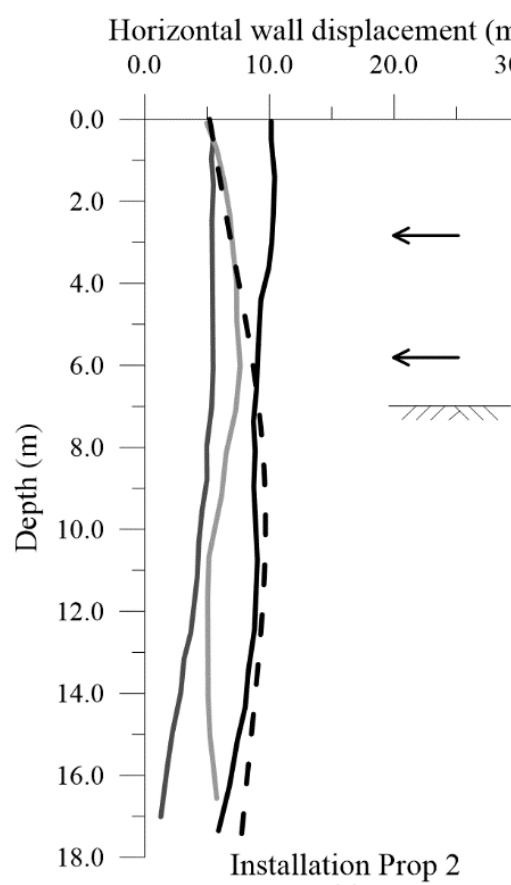

(a)
Horizontal wall displacement $(\mathrm{mm})$

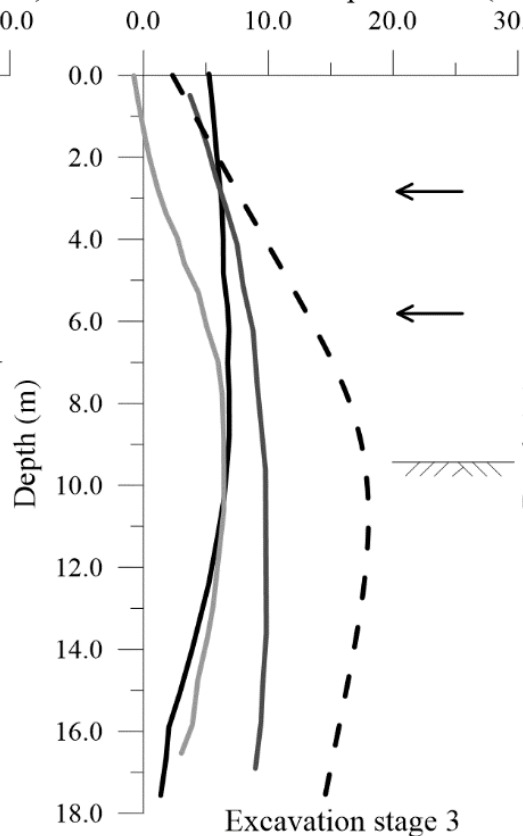

(b)
Horizontal wall displacement (mm)

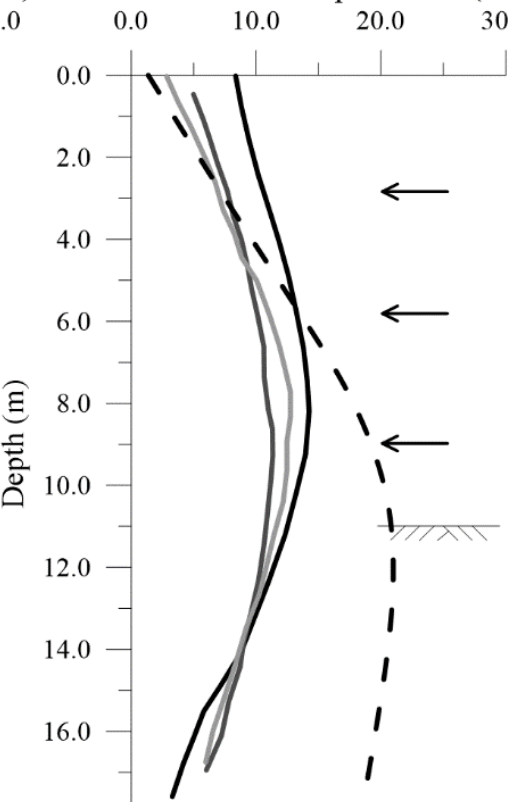

Installation'prop 3

(c)

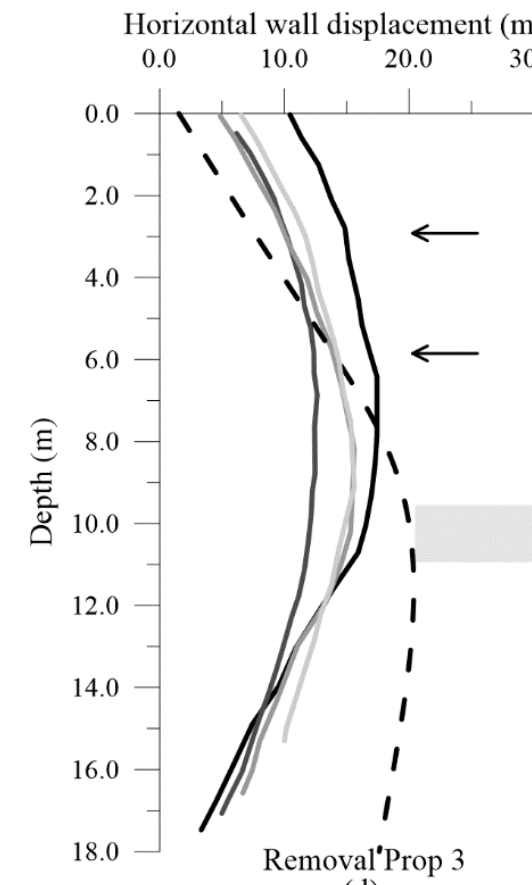

(d)
Horizontal wall displacement (mm)

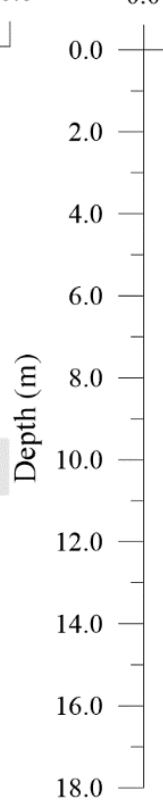

18.0
Construction stage 2

(e)

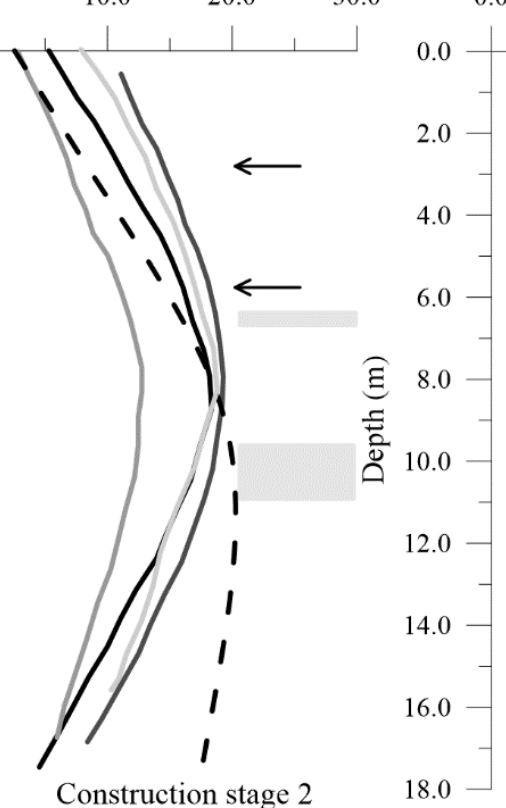

Horizontal wall displacement $(\mathrm{mm})$

$\begin{array}{llll}0.0 & 10.0 & 20.0 & 30.0\end{array}$

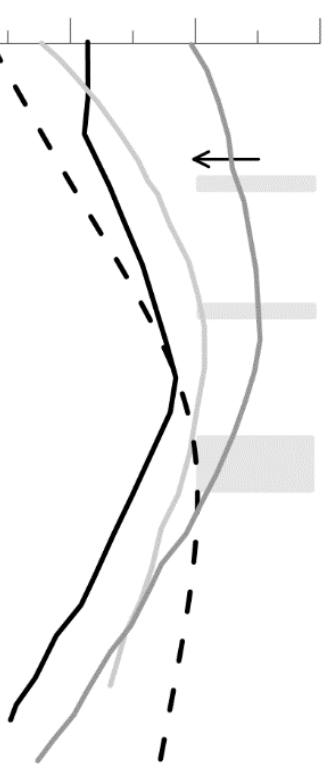

Construction stage 3

(f)

i $1-$ i $3 \longrightarrow$ i $4-$ i $7--$ FE analysis $\longleftarrow$ Prop $7 \lambda$ Excavation level Concrete structure

Figure 4: Comparison between measured and simulated horizontal wall displacement at given simulation stages (a) installation prop 2, (b) excavation stage 3, (c) installation prop 3, (d) removal prop 3, (e) construction stage 2 and (f) construction stage 3 


\section{Thermo-hydro-mechanical analysis}

The same numerical model described in the previous section was used to perform further FE analyses hypothesising that the wall was subjected to thermal loads. Therefore, a fully coupled thermo-hydromechanical analysis was carried out, aiming at providing insight into the behaviour of this structure in the short and long term and identifying the factors which control its transient behaviour. In addition, simplified analyses are presented where some components of the THM formulation are inactive, highlighting the relative contribution of the different mechanisms taking place during the operation of this wall as a heat exchanger. Moreover, these analyses characterise the implications to the design of these structures of adopting different modelling approaches.

\subsection{Fundamental aspects of THM analyses}

\subsubsection{Development of thermal strains}

In a THM analysis (see e.g. Cui et al., 2018), the total strains $\left(\varepsilon_{t o t}\right)$ are given by the sum of the mechanical $\left(\varepsilon_{\text {mech }}\right)$ and thermal strains $\left(\varepsilon_{t h}\right)$. While the latter are associated to the thermal expansion/contraction of the material when subjected to temperature changes, the former relate to changes in stress state, even when these arise from thermal loading. For example, when heating a confined material, the mechanical strains would have the same magnitude but opposite sign of the thermal strains, such that the total strains remain equal to zero to satisfy the boundary conditions. The mechanical strains would therefore be associated with a change in the stress state, which would be termed "thermally-induced", despite not being connected to the thermal strains. These concepts are used throughout this paper to interpret the simulated coupled THM soil behaviour and its impact on the response of the wall.

A useful parallel can be drawn with thermo-active piles, for which a simplified framework for understanding their behaviour under thermal loads has been proposed (see Amatya et al. (2012) and Bourne-Webb et al. (2013)). According to this approach, the main factor influencing the mechanical response of thermo-active piles when subjected only to changes in temperature is the magnitude of the so called "restrained strain", $\varepsilon_{t h-r e s t r a i n e d}$, which is defined as the part of the free thermal strain, $\varepsilon_{t h-f r e e}$, that is impeded from developing due to the restriction imposed to the structure either by the soil or end restraints and which causes loads to develop:

$$
\varepsilon_{\text {th-restrained }}=\varepsilon_{\text {th-free }}-\varepsilon_{o b s}
$$

where $\varepsilon_{o b s}$ is the actual observed strain. Note that, as expected in the case of a thermo-active pile, all the strains in Equation (2) are considered to be in the axial direction. Therefore, it is clear that the free thermal strain $\left(\varepsilon_{t h-f r e e}\right)$ is simply the axial component of the thermal strain in a THM analysis $\left(\varepsilon_{t h}\right.$, see above). Similarly, the restrained strain in Equation (2), which encapsulates the effects of any restraint on the pile, is identical to the previously defined mechanical strain $\left(\varepsilon_{\text {mech }}\right)$, though with opposite signs $\left(\varepsilon_{\text {mech }}=-\varepsilon_{\text {th-restrained }}\right)$, given their distinct nature (the former represents a thermal strain that did not develop, while the latter refers to the action responsible for suppressing the deformation). Lastly, given these definitions, it can be concluded that $\varepsilon_{o b s}=\varepsilon_{t o t}$, i.e. both denote the combined effect of the mechanical and thermal strains.

Clearly, the framework proposed by Amatya et al. (2012) and Bourne-Webb et al. (2013) needs to be slightly modified if applied to thermo-active retaining walls. For example, for the case of thermo-active piles, the free thermal strain (i.e. if no restraint to the pile would exist) is simply determined as $\varepsilon_{t h-\text { free-pile }}=\alpha_{c} \Delta T$, where $\alpha_{c}$ is the linear coefficient of thermal expansion of the concrete and $\Delta T$ is the temperature change. Consequently, any mechanical strains calculated in a pile subjected only 
to a thermal load must be directly associated to changes in axial stresses. However, for a retaining wall modelled in a $2 \mathrm{D}$ plane strain analysis the above relationship cannot be directly applied due to the restriction to its deformation in the out-of-plane direction. In effect, in such a situation, there will be a contribution of the Poisson's ratio, $\mu$, to the free axial strain of the wall due to a temperature change, $\varepsilon_{\text {free-wall }}$ :

$$
\varepsilon_{\text {free-wall }}=\alpha_{c} \Delta T+\mu \alpha_{c} \Delta T
$$

Note that, despite its thermal origin, this strain should not be designated as such, since the second term in Equation (3) is a mechanical strain which arises from the increase in stress in the out-of-plane direction. As a result, in the analysis of a thermo-active retaining wall the following aspects of its behaviour be needs to be considered:

(a) the potential strain developed due to temperature changes (i.e. the free strain) is larger than that of a thermo-active pile, with the difference depending on the Poisson's ratio of concrete;

(b) the axial mechanical strain is not equivalent to the restrained strain since the former includes the contribution of the mechanical restraint in the out-of-plane direction.

\subsubsection{Generation of excess pore water pressures}

The formulation of the hydraulic equation under non-isothermal conditions is expressed in ICFEP through the following equation (Cui, 2015; Cui et al., 2018):

$$
-\nabla \cdot\left\{v_{f}\right\}+\frac{n}{K_{f}} \frac{\partial p_{f}}{\partial t}-\underbrace{3 n\left(\alpha_{w}-\alpha_{s}\right) \frac{\partial T}{\partial t}}_{(i)}+Q^{f}=\underbrace{\frac{\partial\left(\varepsilon_{v, t o t}-\varepsilon_{v, t h}\right)}{\partial t}}_{(i i)}
$$

where $v_{f}$ is the vector of seepage velocity, $n$ is the porosity, $K_{f}$ is the bulk modulus of the pore fluid, $\alpha_{w}$ and $\alpha_{s}$ are respectively the thermal expansion coefficients of the pore water and the soil skeleton, $T$ is temperature, $Q^{f}$ is any source or sink of pore fluid, $\varepsilon_{v, t o t}$ and $\varepsilon_{v, t h}$ are respectively the total and thermal volumetric strains (note that $\varepsilon_{v \text {,tot }}-\varepsilon_{v, t h}=\varepsilon_{v, m e c h}$ ), and $t$ is time. Note that this equation adopts a compression positive sign convention, as opposed to the one presented in Cui et al. (2018). In this equation, if the source/sink term is disregarded, there are two terms which are responsible for the generation of excess pore water pressures in a coupled THM analysis. The first, labelled as (i), arises from the results of various experimental studies where a pore water pressure build up was measured in soil samples subjected to temperature changes under undrained conditions (e.g. Campanella and Mitchell, 1968; Abuel-Naga et al., 2007). This is attributed to the difference between the linear coefficients of thermal expansion of soil $\left(\alpha_{s}\right)$ and water $\left(\alpha_{w}\right)$, with the latter being larger than the former, leading to increases in pore water pressures during heating and the opposite during cooling. The second mechanism, labelled as (ii), establishes the generation of excess pore water pressures due to the variation of pore space arising from mechanical volumetric strains, expressed in this case by the difference between total and thermal volumetric strains, as explained in the preceding section. Note that this term describes the hydro-mechanical coupled behaviour and is independent of whether heat transfer is being considered (i.e. it is present even in isothermal analysis). In this paper, when explaining in detail the soil-structure interaction phenomena associated with the operation of thermo-active retaining walls, the pore water pressures generated through mechanism (i) will be designated as "thermally-induced", while those resulting from mechanism (ii) will be termed "mechanically-induced". Note that the latter terminology applies in cases where the mechanical strains are due to applied loads and/or a temperature change (e.g. thermal expansion). 


\subsection{Details of the analyses}

The finite element mesh, the mechanical and hydraulic boundary conditions and material properties adopted in the thermo-hydro-mechanical analyses are the same as those outlined in Section 2, which were deemed appropriate given the good agreement between the simulated and measured response of the considered retaining wall. The thermal material properties were adopted from Gawecka et al. (2017) and are presented in Table 2. The initial temperature of the ground was set to $13^{\circ} \mathrm{C}$, as measured for a site in East London (Loveridge et al., 2013).

Once construction was completed, the diaphragm wall and internal structures were loaded assuming a surcharge corresponding to $10 \mathrm{kPa}$ per storey of the building. This load was applied to the floor slab and the wall at ground level. In addition, a surcharge of $20 \mathrm{kPa}$ was applied to each of the basement slabs. In order to simulate the presence of the drainage system reported by Wood \& Perrin (1984a), a pore water pressure of $0 \mathrm{kPa}$ was prescribed along the underside of the base slab. Before the application of any heat load, the excess pore water pressures generated during the previous stages (excavation, construction and loading) were fully dissipated through consolidation. While realistically any GSES would be expected to start operating soon after the completion of the building, this dissipation stage was deemed necessary in order to facilitate the interpretation of the THM behaviour of the retaining wall by isolating it from the effects of previous construction stages. Furthermore, it should be noted that, since the application of the thermal load generally implies a reversal of the loading direction, the stiffness of all soils was reset to its maximum value prior to any changes in temperature being applied (see Gawecka et al. (2017) for additional details on this procedure).

Mechanical and hydraulic boundary conditions were specified as described in the previous section. In terms of thermal boundary conditions, no heat flux was allowed across the bottom and lateral boundaries of the domain, while the temperature at the ground surface was assumed to remain constant throughout the analysis. Moreover, no heat transfer through the internal structures was modelled, meaning that a perfect insulation barrier was simulated, preventing any heat losses from the soil to the basement. To simulate the heat load applied to the retaining wall, a prescribed uniform temperature change of $15^{\circ} \mathrm{C}$ over 10 days (i.e. $1.5^{\circ} \mathrm{C} /$ day) was applied to all elements of the diaphragm wall, with the final temperature being kept constant for 10 years. Clearly, this does not reproduce a realistic operation mode for a GSES, where the heat load varies monthly or even daily. Additionally, representing the heat exchange by prescribing a uniform temperature over the whole wall neglects factors such as pipe arrangement, advection within the pipes, non-uniform temperature distribution along the pipe and the heat conduction through the concrete. However, both the long-term heating of the wall and the use of uniform temperature changes enable a clearer assessment of the fundamental soil-structure interaction mechanisms that take place due to thermal load application, establishing the base knowledge upon which further research may be carried out with more realistic operation modes and thermal load application methodologies.

\begin{tabular}{l|c|c|c|c|c|c} 
Material & $\begin{array}{c}\gamma_{s} \\
{\left[\mathrm{kN} / \mathrm{m}^{3}\right]}\end{array}$ & $\begin{array}{c}\alpha_{s} \\
{[\mathrm{~m} / \mathrm{mK}]}\end{array}$ & $\begin{array}{c}\alpha_{w} \\
{[\mathrm{~m} / \mathrm{mK}]}\end{array}$ & $\begin{array}{c}K_{f} \\
{[\mathrm{GPa}]}\end{array}$ & $\begin{array}{c}\rho C_{p} \\
{\left[\mathrm{~kJ} / \mathrm{m}^{3} \mathrm{~K}\right]}\end{array}$ & $\begin{array}{c}\lambda \\
{[\mathrm{W} / \mathrm{mK}]}\end{array}$ \\
\hline Concrete & 24.0 & $8.5 \times 10^{-6}$ & $--\left(^{*}\right)$ & $--(*)$ & 1920 & -- \\
\hline Made Ground & 18.0 & $1.7 \times 10^{-5}$ & $-\left(^{*}\right)$ & $-\left(^{*}\right)$ & 1900 & 1.40 \\
\hline Terrace Gravel & 20.0 & $1.7 \times 10^{-5}$ & $-\left(^{*}\right)$ & $--\left(^{*}\right)$ & 1900 & 1.40 \\
\hline London Clay & 20.0 & $1.7 \times 10^{-5}$ & $6.9 \times 10^{-5}$ & 2.2 & 1820 & 1.79 \\
\hline Lambeth Group Clay & 20.0 & $1.7 \times 10^{-5}$ & $6.9 \times 10^{-5}$ & 2.2 & 1760 & 2.20 \\
\hline Thanet Sand & 20.0 & $1.7 \times 10^{-5}$ & $--\left(^{*}\right)$ & $--\left(^{*}\right)$ & 1760 & 2.40 \\
\hline
\end{tabular}

$(*)$ parameter not required since stratum is considered fully drained 
Different analyses were performed to characterise the behaviour of a diaphragm wall subjected to a thermal load and to evaluate the influence of different modelling approaches on the results. These are summarised in Table 3 and are as follows:

- THM analysis: a fully coupled transient THM analysis where heat transfer, thermally-induced material expansion and pore water pressure build-up and pore water pressure dissipation are simulated, providing the most realistic representation of a thermo-active wall problem;

- HM analysis: a coupled hydro-mechanical analysis in which there is no heat transfer to the soil, meaning that temperature effects are restricted to the thermal expansion of the wall. This analysis enables the assessment of the influence of soil thermal expansion and thermallyinduced pore water pressures on soil-structure interaction;

- dTM analysis: a drained coupled thermo-mechanical analysis where no changes in pore water pressures take place (i.e. neither due to temperature changes nor due to hydro-mechanical coupling), but the soil is able to thermally expand. It allows the quantification of the effects of thermal soil expansion when compared to the results of the HM analysis. Similarly, when compared to the THM analysis, it provides insight into the impact of mechanically and thermally-induced pore water pressures;

- UTM analysis: an undrained coupled thermo-mechanical analysis in which only the behaviour of the soil-fluid mixture is considered (i.e. the two-phase nature of the soil is neglected, implying that $\alpha_{w}=\alpha_{s}$ ), hence excess pore water pressures are only generated as a consequence of changes in mechanical volumetric strain (term (ii) in Equation 4) and are not allowed to dissipate with time. This analysis provides an assessment of the impact of the generation of thermally-induced pore water pressures and their consequent dissipation on the transient behaviour of the retaining wall.

\begin{tabular}{c|c|c|c|c|c}
$\begin{array}{c}\text { Analysis } \\
\text { code }\end{array}$ & $\begin{array}{c}\text { Transient } \\
\text { seepage }\end{array}$ & $\begin{array}{c}\text { Mechanically-induced } \\
\text { pore water pressures } \\
\left({ }^{*}\right)\end{array}$ & $\begin{array}{c}\text { Transient } \\
\text { heat } \\
\text { transfer }\end{array}$ & $\begin{array}{c}\text { Thermal } \\
\text { expansion } \\
\text { of soil }\end{array}$ & $\begin{array}{c}\text { Thermally-induced } \\
\text { pore water pressures } \\
\left({ }^{*}\right)\end{array}$ \\
\hline THM & Yes & Yes & Yes & Yes & Yes \\
\hline HM & Yes & Yes & No & No & No \\
\hline dTM & No & No & Yes & Yes & No \\
\hline uTM & No & Yes & Yes & Yes & No \\
\hline
\end{tabular}

$\left({ }^{*}\right)$ term (ii) in Equation $4 ;\left({ }^{* *}\right)$ term (i) in Equation 4

Table 3: Summary of the analyses performed

\section{Results}

In this section the results of the aforementioned analyses are presented in terms of pore water pressures and temperature distributions, structural forces, i.e. axial forces and bending moments, and wall displacements and ground movements.

\subsection{Temperatures and pore water pressures}

The temperature distributions for different time instants are depicted in Figure 5. These are equal for the analyses involving heat transfer through the soil, i.e. analysis THM, UTM and dTM, since the thermal parameters remain unchanged and seepage velocities are sufficiently low to mean that there is no measurable impact of advection. With time, the temperatures in the area immediately around the wall steadily increase and propagate further away from the heat source as a consequence of the constant temperature imposed within the wall. It should be noted that higher temperatures develop 
on the left hand side of the wall (i.e. beneath the base slab) as no heat flux was allowed into the building and through the left hand-side boundary, as it is an axis of symmetry. The results show that the latter boundary is sufficiently close to the heat source to induce a build-up of temperatures in that region.

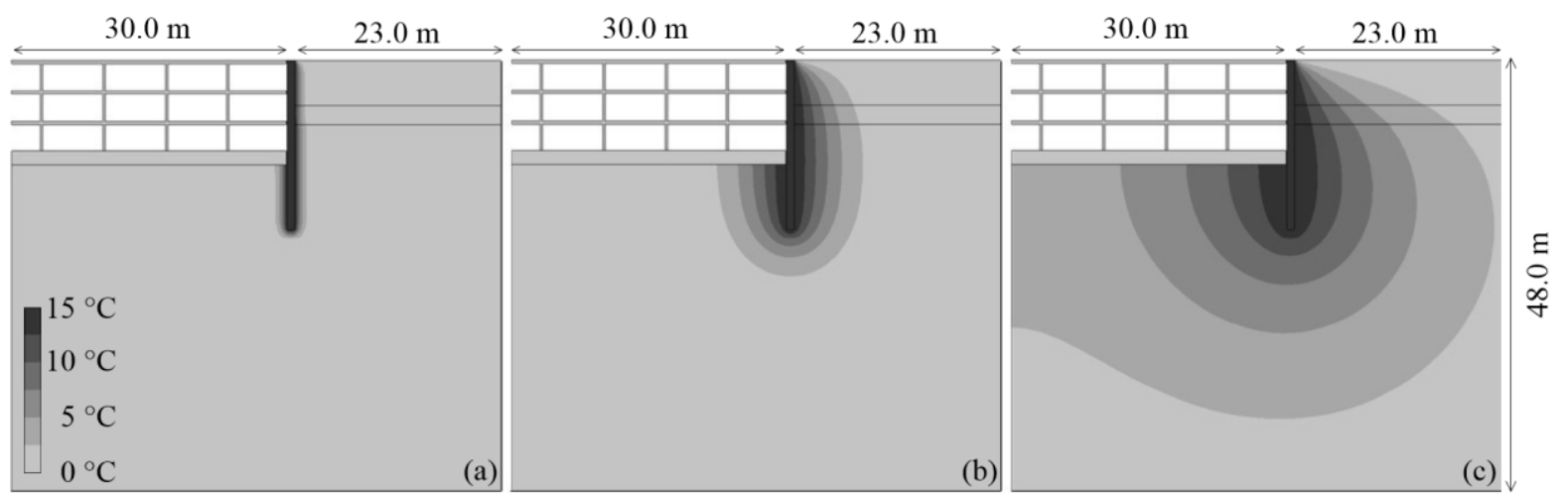

Figure 5: Temperature contours for thermal analyses (a) after 10 days, (b) after 6 months and (c) after 10 years

The changes in pore water pressures for three different time instants, namely after 10 days, 6 months and 10 years of heating, for the THM, HM and UTM analyses are presented in Figure 6, Figure 7 and Figure 8 , respectively. No results are shown for the dTM analysis, since in this case no pore water pressures can be generated.

In the THM analysis, where both wall and soil expand due to heating, compressive excess pore water pressures develop along the shaft and at the bottom of the wall. This is due to the thermal coefficient of expansion of water being greater than that of soil and therefore an increase in temperature induces generation of compressive pore water pressure (term (i) in Equation 4). At the end of heating, i.e. Figure $6(\mathrm{a})$, the maximum value, of $103.0 \mathrm{kPa}$, is registered close to the bottom of the wall, where additional mechanically-induced pore water pressures (term (ii) in Equation 4) are generated due to the expansion of the wall compressing the soil beneath it. With time, as excess pore water pressures dissipate close to the wall, further compressive excess pore water pressures develop within the consolidating materials at greater distances from the heat source. As can be noted in Figure 6 (c), after 10 years, the pore water pressures still increase in regions further away from the structure where greatest changes in temperature take place (see Figure 5 for temperature contours). Concurrently, as a consequence of dissipation, the maximum value along the back of the wall has reduced to $28 \mathrm{kPa}$ after 10 years.

In the HM analysis, since the soil does not undergo thermal expansion, term (i) of Equation 4 is equal to zero and hence, the only observed excess pore water pressures are those due to mechanical deformation of the soil as the wall thermally expands. After 10 days of heating (Figure 7 (a)), suctions develop along the shaft of the wall, whereas compressive pore water pressures are generated beneath the bottom of the structure. These are induced by the thermal expansion of the wall: the soil along most of the shaft is forced to expand in the vertical direction since full friction is simulated along the soil-structure interface, whereas the soil below the toe of the wall is compressed as the wall pushes against it. It can be noticed that the magnitude of the generated pore water pressures is considerably smaller than those observed in the THM analysis: maximum suctions of -20.0 kPa along the shaft and maximum compressive pore water pressures of $22.0 \mathrm{kPa}$ beneath the toe of the wall (thus, approximately $80 \%$ less than in the THM analysis). Considering that the wall expansion is similar in the two analysis, this suggests that the thermally-induced pore water pressures - i.e. due to $\alpha_{w}$ being larger than $\alpha_{s}$ in term (i) of Equation 4 - are approximately $80.0 \mathrm{kPa}$. As there is no heat transfer within 
the soil mass and no associated thermally-induced pore water pressures, hydraulic equilibrium is reached sooner: in fact, after 6 months from the beginning of heating almost full dissipation has taken place (Figure 7 (b)).

In the UTM analysis, the soil mass and the wall expand due to heating, however the clayey materials are treated as undrained, meaning that the pore water pressures are merely induced by a change in mechanical volumetric strain (i.e. term (ii) in Equation 4) and that there is no time-dependent dissipation of excess pore-water pressure. After the first heating phase (Figure 8 (a)), compressive excess pore water pressures are generated due to the expansion of the soil inducing a compressive mechanical volumetric strain. The changes in pore water pressure are however smaller compared to the THM analysis, with a maximum along the shaft of $61.0 \mathrm{kPa}$ close to the toe of the wall (a reduction of $40 \%$ ), because, as shown earlier, a large part of the excess pore water pressures results from the differential thermal expansion of fluid and soil particles, which is neglected in this analysis. With time, since the pore water pressures are not allowed to dissipate, they constantly increase as a result of the propagation of heat and consequent changes in stress. After 10 years, the maximum value registered at the back of the wall increases substantially, reaching values of $104.0 \mathrm{kPa}$.

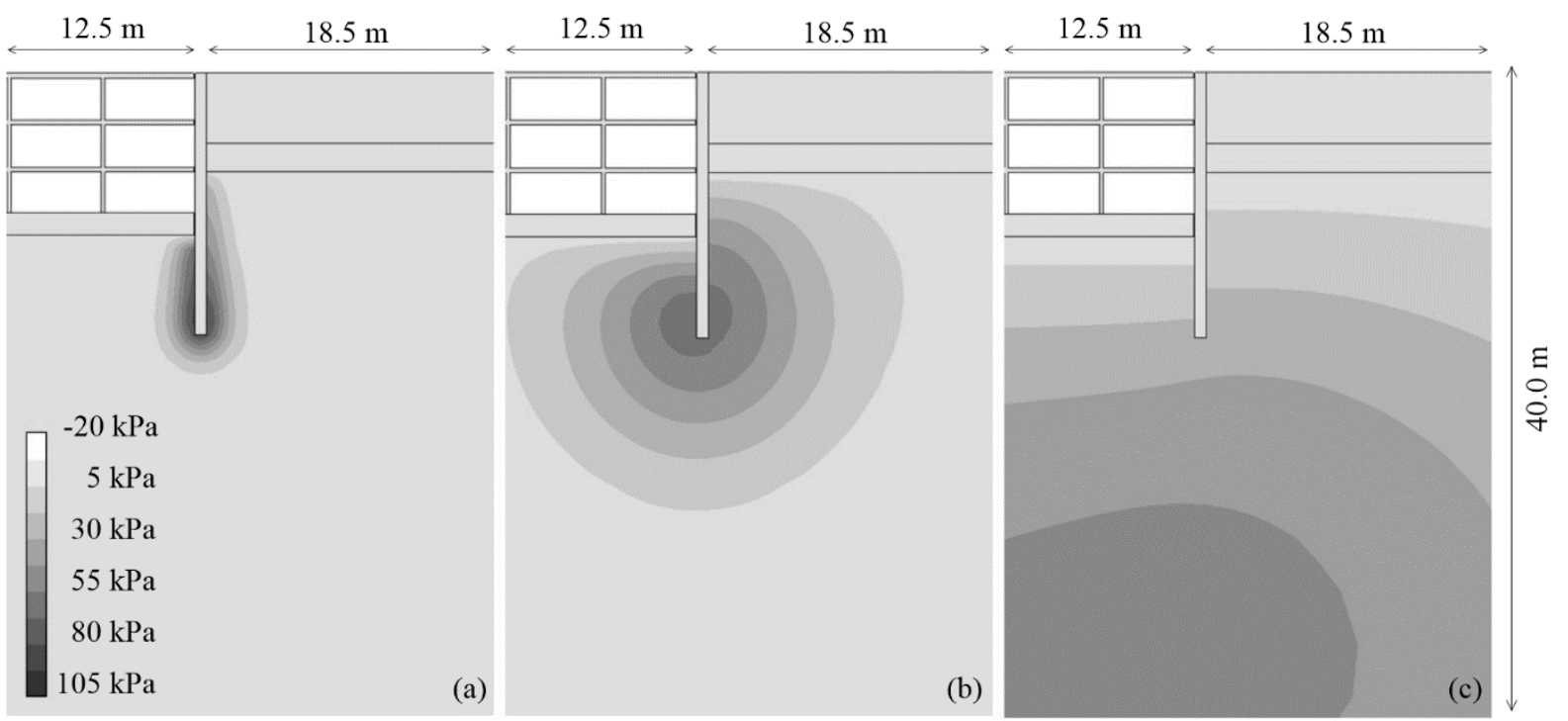

Figure 6: Contours of pore water pressures for THM analysis (a) after 10 days, (b) after 6 months and (c) after 10 years
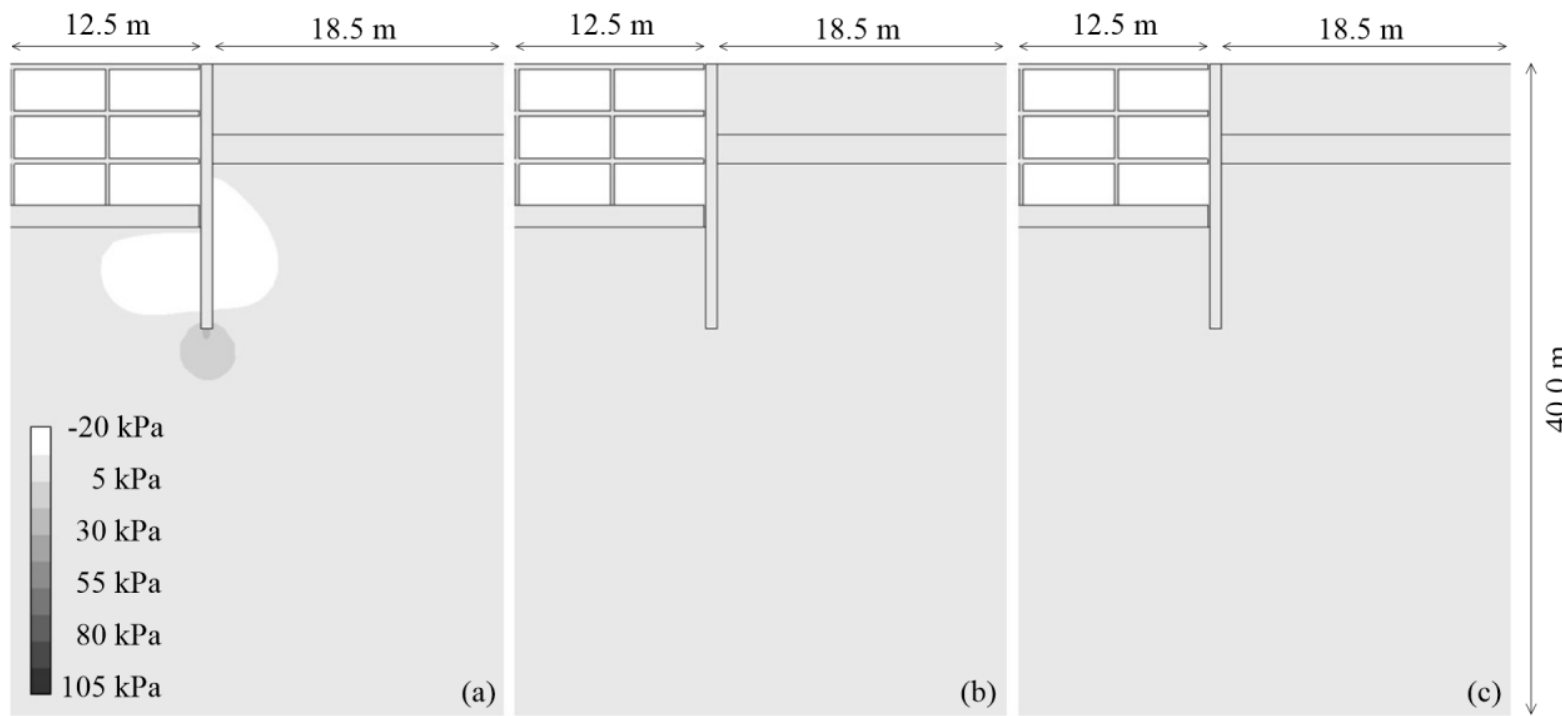

Figure 7: Contours of pore water pressures for HM analysis (a) after 10 days, (b) after 6 months and (c) after 10 years 


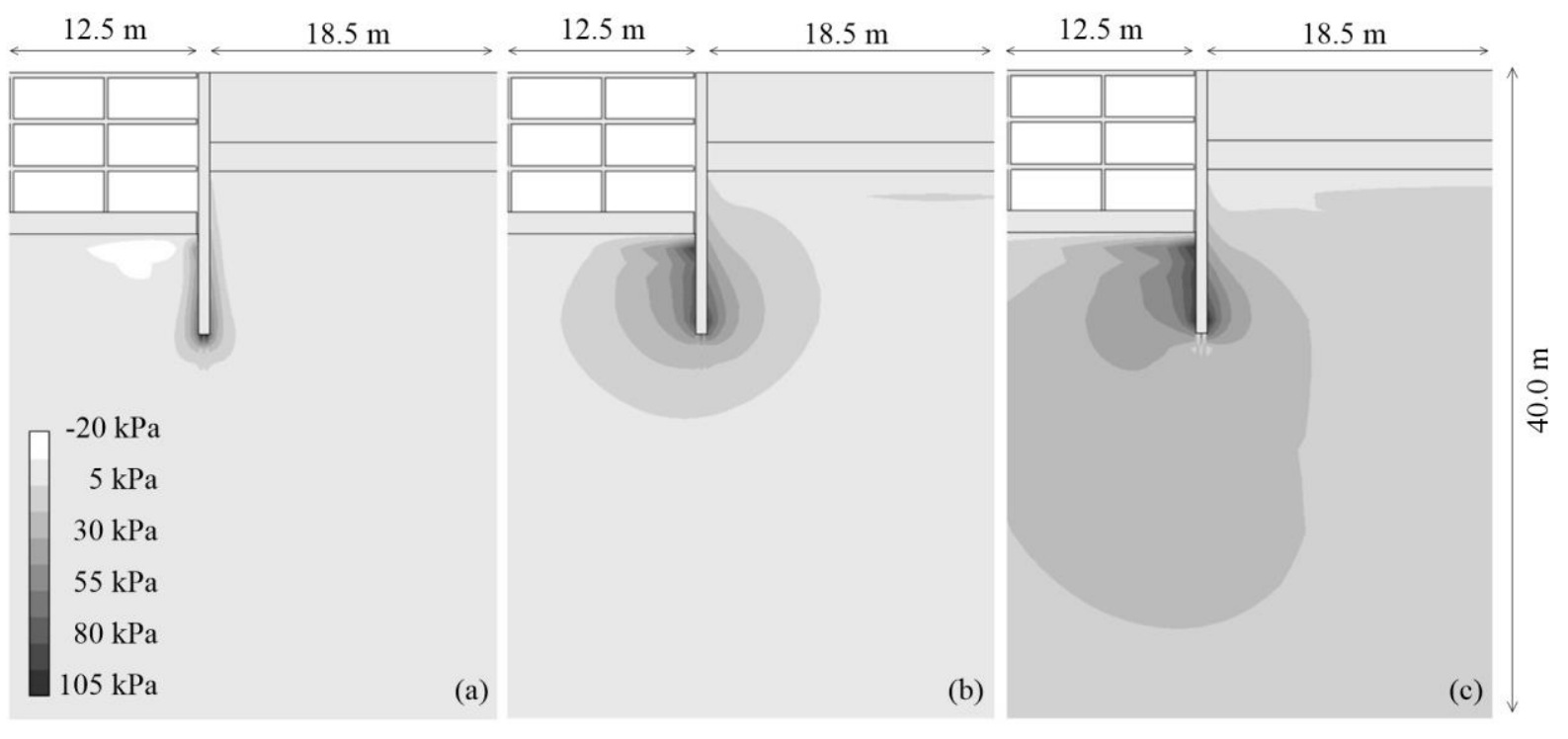

Figure 8: Contours of pore water pressures for UTM analysis (a) after 10 days, (b) after 6 months and (c) after 10 years

\subsection{Structural forces and horizontal wall movements}

Figure 9 shows the thermally induced axial forces along the depth of the wall for different time instants for all the four analyses, whereas Figure 10 shows the development of the axial force with time at a depth $14.0 \mathrm{~m}$ below ground level where, on average, the greatest changes in axial force take place.

From Figure 9 it is evident that the largest changes in axial force take place within the embedded part of the wall, as this is where the structure is more restricted by the soil. In fact, the upper part of the wall experiences a minimal increase in axial force and it is very similar for all the analyses. Moreover, as can be noted in Figure 9 (a), heating induces mechanical compression within the wall in the shortterm (i.e. after 10 days of heating): the structure expands due to heating, however the soil restricts part of this deformation, leading to the development of compressive axial forces. The largest change in axial force at the end of initial heating is recorded in the HM analysis, whereas much lower axial forces are registered during the THM analysis. The different predictions resulting from the four analyses are due to a complex combination of effects:

- The smallest change in axial force (maximum of $-37.0 \mathrm{kN} / \mathrm{m}$ ) is calculated in the THM analysis because, as the soil heats up and expands, it reduces the restriction it applies to the wall. Furthermore, the generation of compressive excess pore water pressures leads to soil swelling, hence inducing further tension within the wall.

- The higher axial forces predicted in the HM analysis (maximum of $-206.0 \mathrm{kN} / \mathrm{m}$ ) are due to the larger restriction the soil applies as it is not thermally active and hence does not expand with temperature. In addition, the tensile pore water pressures imply a compressive mechanical volumetric change of the soil around the wall, which further contributes to an increase in axial force. However, it should be noted that the effect of this is limited as the magnitude of the pore water pressures is very small in this analysis.

- In the dTM analysis, no pore water pressures are generated but the soil thermally expands, releasing part of the restriction of the soil, explaining the lower axial force when compared to that of the HM analysis (maximum of $-126.0 \mathrm{kN} / \mathrm{m}$ ). It is interesting to note that the difference between this analysis and the THM is merely given by the absence of pore water pressure generation in the former. Therefore, the fact that the average force along the embedded part is $98.0 \mathrm{kN} / \mathrm{m}$ larger in the dTM analysis provides an insight into the substantial contribution of soil swelling due to pore water pressure generation to the releasing of the restriction applied 
to the wall. On the other hand, the difference between the HM and dTM analysis indicates the effect of soil expansion on the axial force. Within the embedded section, the predicted axial force in the dTM analysis is, on average, $62.0 \mathrm{kN} / \mathrm{m}$ lower with respect to the one registered in the $\mathrm{HM}$ analysis, hence suggesting that thermal volumetric changes of the soil have a more limited effect on the development of axial forces when compared to that of pore water pressures.

- The calculated axial forces of the UTM analysis are similar to the dTM, since in the short term the behaviour is mainly controlled by expansion of the soil, which is equal in both analyses.

After the imposed temperature change of $15^{\circ} \mathrm{C}$ is reached, it can be noticed from Figure 9 (b) and (c), as well as from Figure 10, that the analyses display different behaviour in the medium to long term. In the THM analysis, a non-linear transient long-term behaviour can be observed. This is induced by different effects prevailing over different time instants: initially, thermal expansion of the wall is restricted by the soil, inducing compression; subsequently, the structure is subjected to tensile action from soil thermal expansion, whereas, towards the end of the analysis, soil settling due to compressive excess pore water dissipation leads to an increase in compressive axial force in the wall. On the other hand, the remaining analyses display a significantly less non-linear behaviour with time. Indeed, for all the other analyses the compressive axial force merely reduces with time as a consequence of volumetric deformation due to either changes in pore water pressures or soil thermal expansion or a combination of the two. For the HM analysis, the dissipation of tensile excess pore water pressure results in soil swelling, inducing tension in the wall. Indeed, no further changes in axial force are recorded once the excess pore water pressures have dissipated. Conversely, the reduction of the compressive axial force with time in the dTM analysis is due to the soil's thermal expansion which reduces restriction. In addition to this, in the UTM analysis, the constant generation of compressive pore water pressures leads to further soil swelling in addition to the thermal expansion, hence the wall is subjected to larger tensile forces, which, at the end of the analysis, are four times larger than those calculated in the THM analysis.

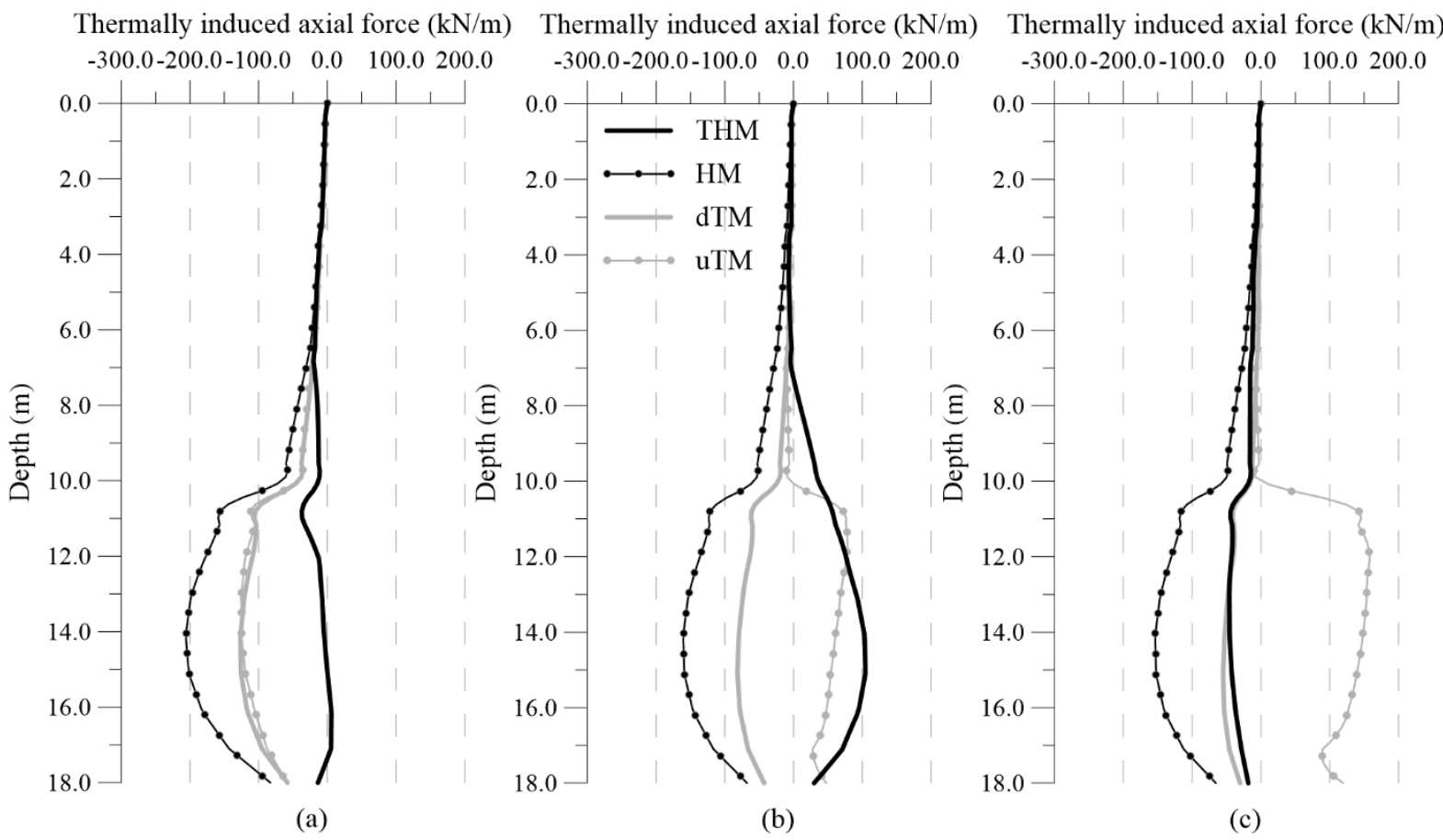


Figure 9: Thermally induced axial force vs depth for all analyses (a) after 10 days, (b) after 6months and (c) after 10 years

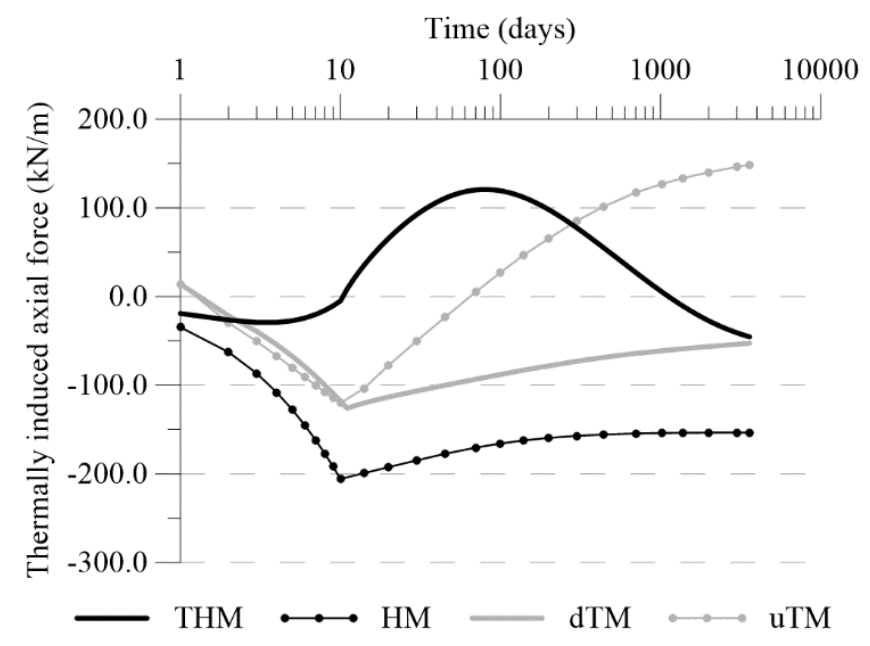

Figure 10: Thermally induced axial force vs time at depth of $14.0 \mathrm{~m} \mathrm{bg} /$ for all analyses

Figure 11 depicts the thermally induced bending moments with depth, which are directly related to the horizontal wall movements shown in Figure 12. These are naturally due to volumetric changes in the soil induced by changes in temperature and pore water pressures. Therefore, the low bending moments observed in the HM analysis are perhaps unsurprising since the soil does not thermally expand and the generated pore water pressures are low. It can be noted that in the short term (i.e. Figure 11 (a)), the bending moments and horizontal displacements are largest for the THM analysis, because in this simulation the largest pore water pressures are generated (refer to Section 4.1). The maximum bending moment, of $51.0 \mathrm{kNm} / \mathrm{m}$, takes place at the position of the base slab. Conversely, in the long term, the largest bending moments are calculated for the uTM analysis, which, after 10 years, presents a maximum positive bending moment of $168.0 \mathrm{kNm} / \mathrm{m}$, which is in excess of four times the one predicted in the THM analysis. As stated earlier, this occurs due to larger soil swelling caused by the continuous building up of excess pore water pressures during the UTM analysis (see Figure 7), which is also confirmed by the horizontal displaced shapes shown in Figure 12.

The evolution with time of the bending moment at the level of the base slab (where the largest positive bending moment is calculated) for the different analyses is displayed in Figure 13. Similar to the axial forces, the evolution of the bending moment with time in the THM analysis is highly non-linear because it is affected by phenomena which occur simultaneously and at different rates, such as soil thermal expansion and dissipation of excess pore water pressures. On the other hand, a reduced number of phenomena take place in the simpler analyses. 


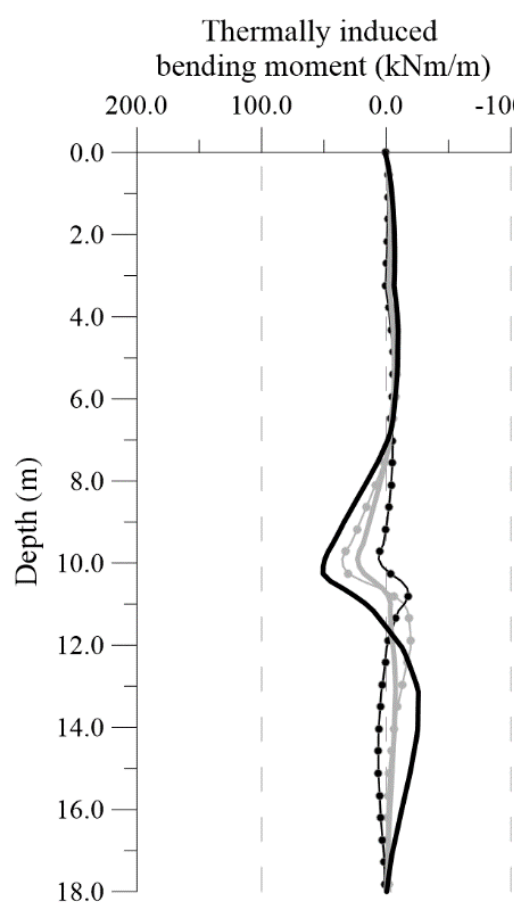

(a)

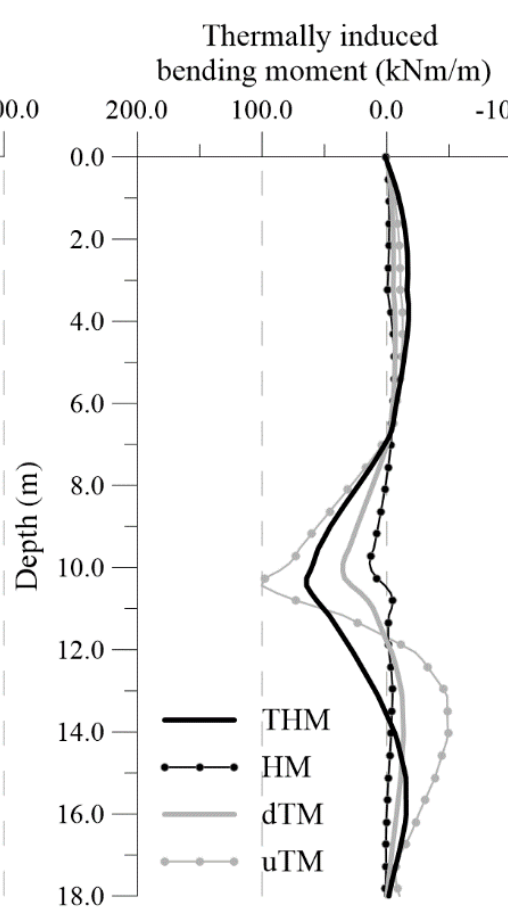

(b)

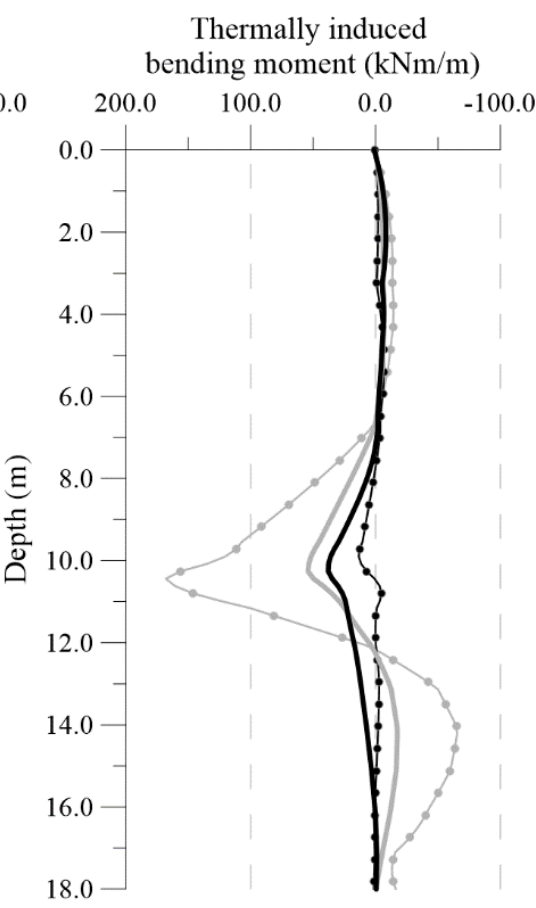

(c)

Figure 11: Thermally induced bending moment vs depth for all analyses (a) after 10 days, (b) after 6 months and (c) after 10 years

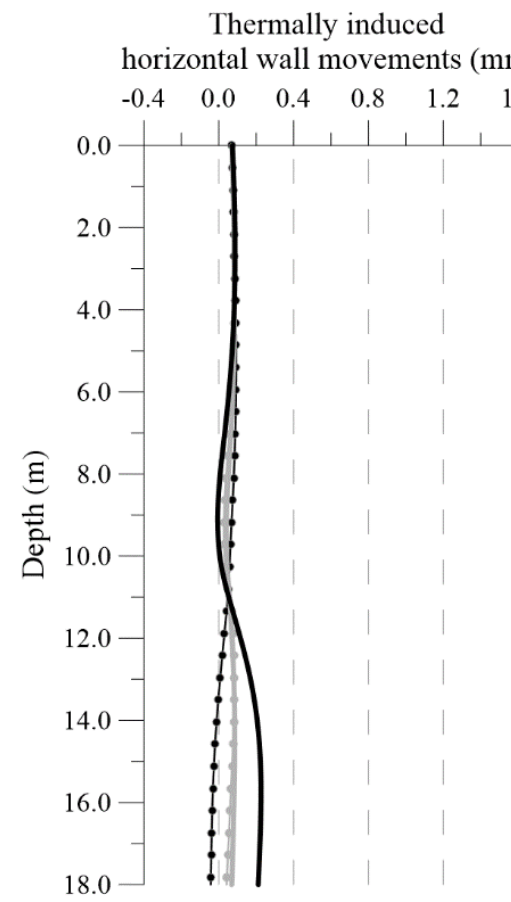

(a)
Thermally induced horizontal wall movements $(\mathrm{mm})$ $\begin{array}{llllll}-0.4 & 0.0 & 0.4 & 0.8 & 1.2 & 1.6\end{array}$

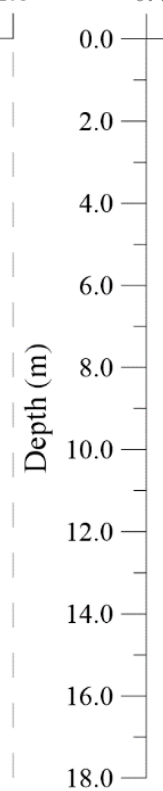

18.0

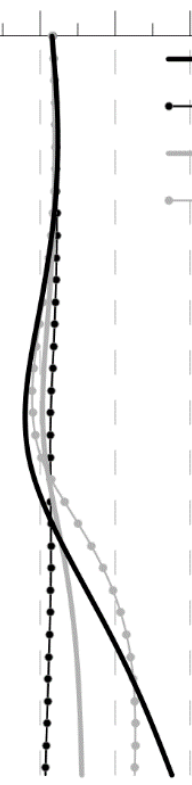

(b)
Thermally induced horizontal wall movements (mm)

$\begin{array}{llllll}-0.4 & 0.0 & 0.4 & 0.8 & 1.2 & 1.6\end{array}$

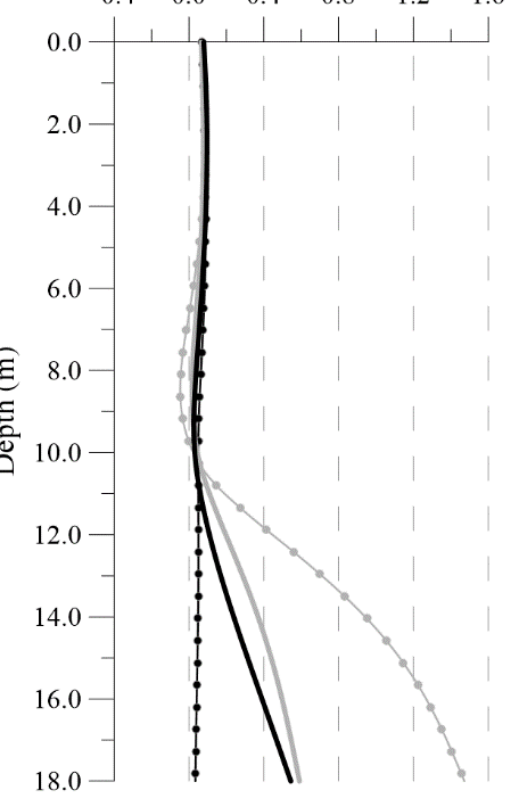

(c)

Figure 12: Thermally induced horizontal wall movements vs depth for all analyses (a) after 10 days, (b) after 6 months and (c) after 10 years 


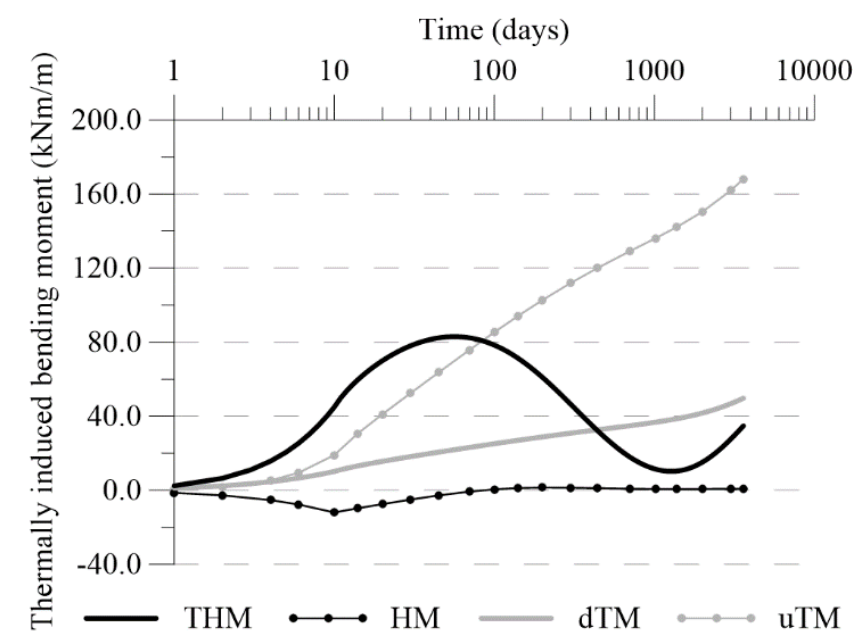

Figure 13: Thermally induced bending moment vs time at depth of $10.5 \mathrm{~m} \mathrm{bgl}$

The effect of thermally-induced forces on the overall performance of the wall was analysed by comparing the total axial force and total bending moment computed during the THM analysis at different time instants after heating to the ones registered before changes of temperature are applied (i.e. after excavation, building loading and pore water pressure dissipation). On average, along the embedded part of the wall, variations in axial force ranged from a reduction of about $25 \%$ to an increase of about $10 \%$, depending on the considered time instant (see Figure 10). Similarly, increases in bending moments were limited to $7 \%$ after 6 months of heating with respect to the bending moments calculated during the previous stages. Although these changes do not appear to be very significant, it should be noted that the magnitude of the thermally induced structural forces will be highly dependent on the connection to the internal structures and the restraint imposed at the top of the wall. Furthermore, different modelling techniques for modelling heat exchange, as well as boundary conditions along the exposed face of the wall, will influence the development of the structural forces within the wall. Lastly, it should also be noted that the use of thermo-active base slabs, which may be installed in conjunction with a thermo-active retaining wall, will induce further forces into the wall. Therefore, these results do not imply that thermal loads do not have significant effects on structural forces; on the contrary, the results discussed in this paper demonstrate that further research is required to confirm their effect on the design of thermo-active retaining walls.

\subsection{Vertical wall and ground displacements}

Vertical displaced shapes of the wall for all analyses and different time instants are shown in Figure 14, while Figure 15 depicts the vertical movements of the top of the wall with time.

The initial temperature change of $15^{\circ} \mathrm{C}$ induces an elongation $\Delta L$ of the wall in all the analyses. The free expansion of the wall $\Delta L_{\text {free }}$ can be determined using:

$$
\Delta L_{\text {free }}=\varepsilon_{\text {free-wall }} \cdot L_{\text {wall }}
$$

where $\varepsilon_{\text {free-wall }}$ is obtained from Equation 3 and $L_{\text {wall }}$ is the total length of the wall $(18 \mathrm{~m})$, resulting in an elongation of $2.984 \mathrm{~mm}$ when the effect of the restriction applied by the soil is not considered. Although the lines in Figure 14 (a) appear to be parallel, there is a slight difference in their gradient, meaning that the value $\Delta L$ is different for the various analyses. In the THM analysis, this value is in fact highest and very close to $\Delta L_{\text {free }}$, explaining the limited increase in axial force. As can be expected, 
since the axial forces are highest for the HM analysis, the value of $\Delta L$ is the smallest among the four considered analyses.

At the end of initial heating, i.e. after 10 days, the displacement of the top of the wall is different for the analysed cases (see Figure 15), because the wall moves not only due to its thermal expansion but also as a consequence of soil deformation due to changes in temperature and pore water pressures. With time, in the analyses where heat transfer in the soil is simulated, the wall keeps moving upwards for a longer period due to the ongoing thermal soil expansion. However, the wall itself is subjected to limited elongation, as can be concluded from the gradient of the displaced shapes not changing between Figure 14 (b) and (c). Moreover, it is interesting to note that larger movements are observed in the UTM analysis with respect to the dTM analysis, an effect attributed to soil swelling caused by the increase in pore water pressures in the former analysis. In the HM analysis, as clearly shown in Figure 15, no changes are observed after the initial heating phase due to the almost absence of time dependent phenomena (no thermal expansion and very limited pore water pressure dissipation, see Figure 6). The largest vertical movement of the top of the wall is observed for the THM analysis, reaching a value of $11.6 \mathrm{~mm}$ after 10 years.

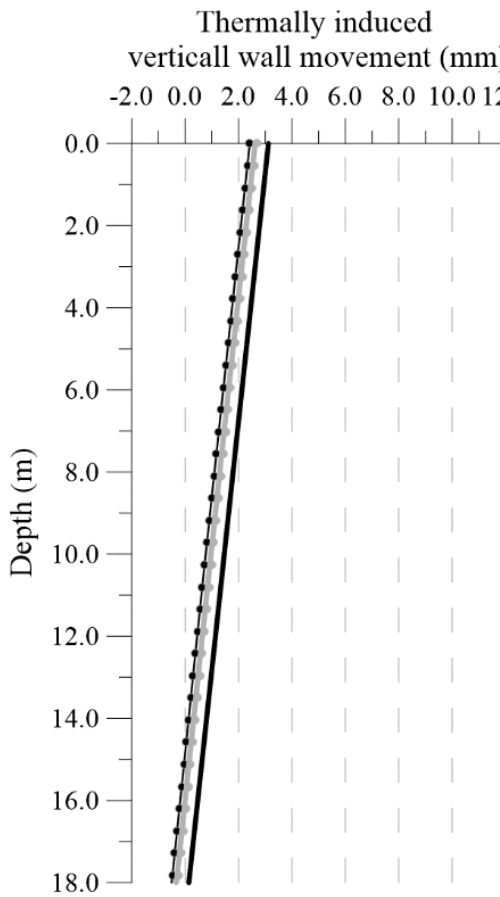

(a)

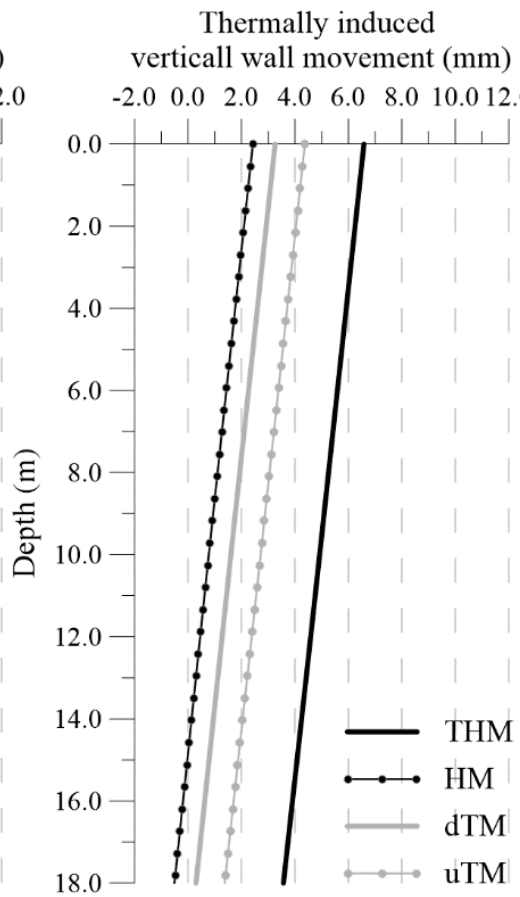

(b)
Thermally induced verticall wall movement $(\mathrm{mm})$ $\begin{array}{llllllll}-2.0 & 0.0 & 2.0 & 4.0 & 6.0 & 8.0 & 10.0 & 12.0\end{array}$

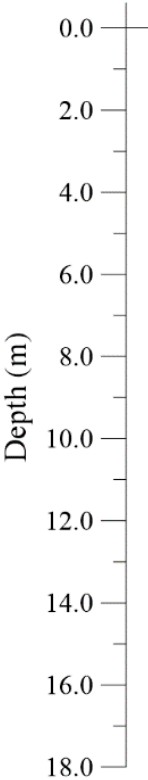

18.0

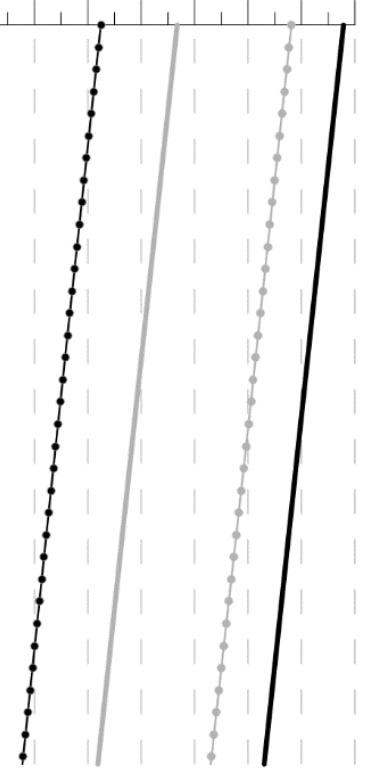

(c)

Figure 14: Thermally induced vertical displaced shapes for all analyses (a) after 10 days, (b) after 6 months and (c) after 10 years 


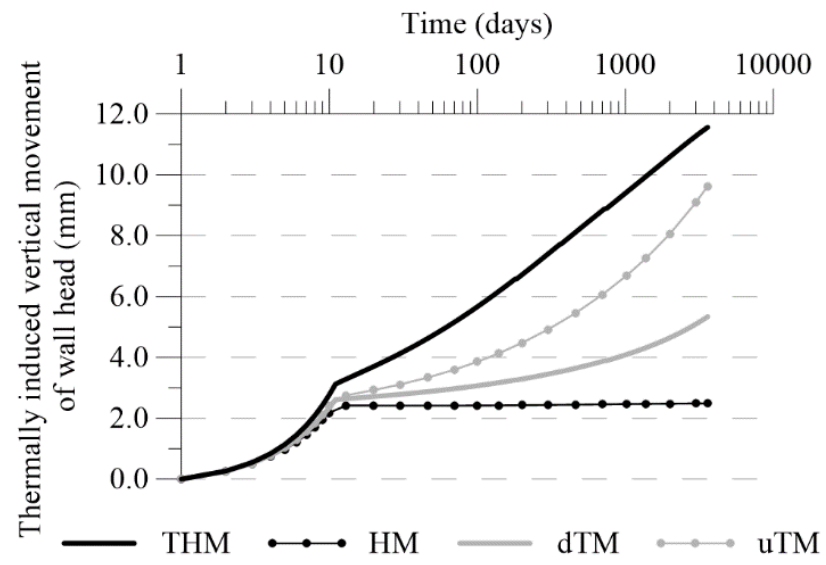

Figure 15: Thermally induced vertical wall displacements of top of wall vs time for all analyses

The vertical movements of the ground surface behind the wall after 10 days and 10 years from beginning of heating are shown in Figure $16(a)$ and (b), respectively. The conclusions are similar to those outlined for the vertical wall displacements, with a maximum value of $11.6 \mathrm{~mm}$ being calculated close to the wall for the THM analysis after 10 years. Furthermore, the ground surface displacements extend to a significant distance behind the wall (e.g. at $20.0 \mathrm{~m}$ from the wall a value of $6.5 \mathrm{~mm}$ is obtained), suggesting a substantial area of influence of the analysed thermo-active structure. While in a real application such a magnitude may not be measured, as it is a consequence of the application of a constant temperature for a long period of time, these results highlight that for structures involving heat exchange with the ground, wall and ground movements should be carefully assessed in order to verify their serviceability and possible interactions with any neighbouring structures that might be affected by ground movements.

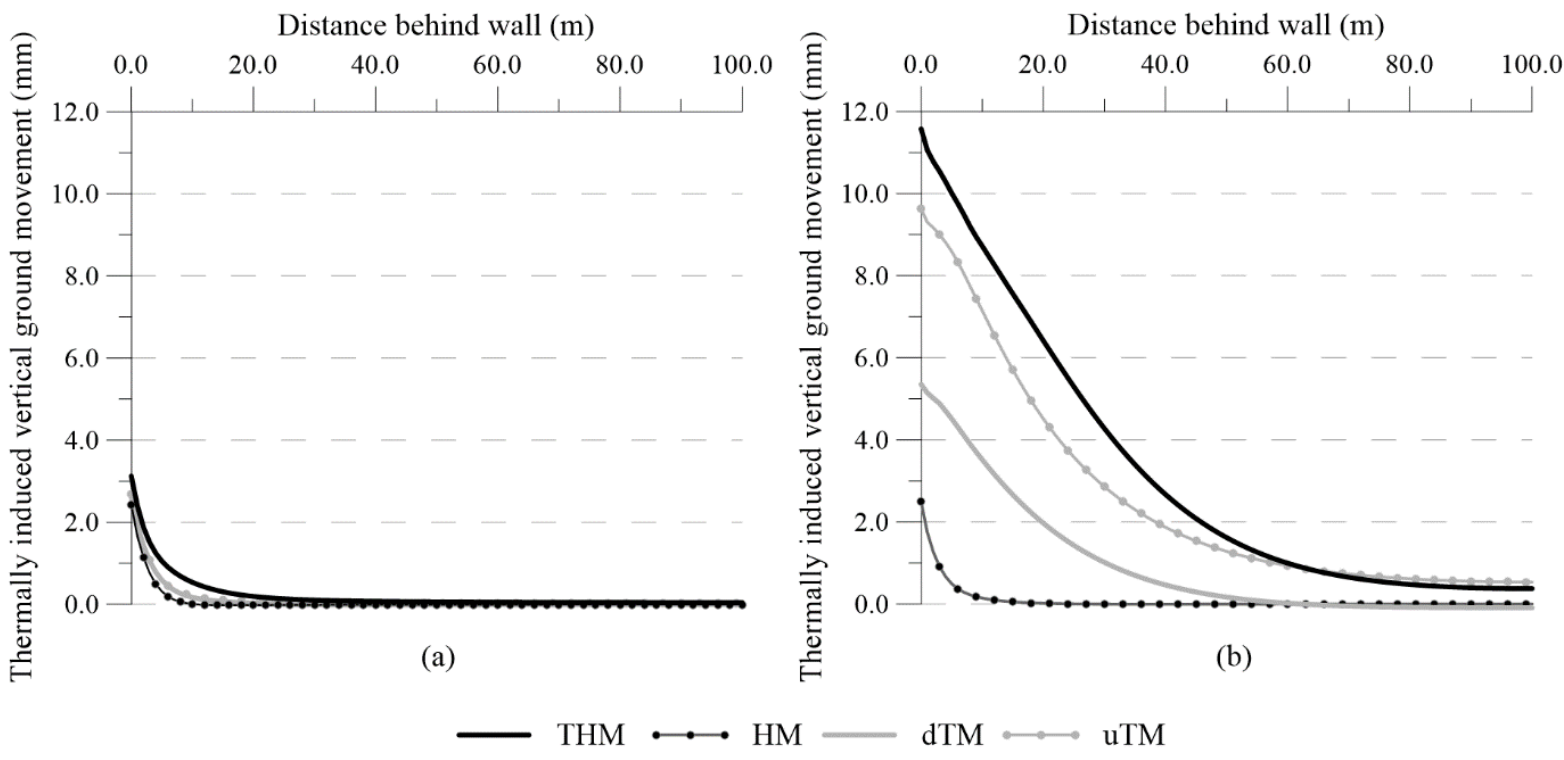

Figure 16: Thermally induced vertical surface ground movements vs distance behind wall (a) after 10 days and (b) after 10 years

\section{Conclusions}

This paper provides insight into the complex thermo-hydro-mechanical phenomena governing the behaviour of a thermo-active diaphragm wall, both in the short term and in the long term. A series of numerical finite element analyses were performed using ICFEP (Potts \& Zdravković, 1999) on a 
hypothetical thermo-active diaphragm wall installed in London. In order to assess the validity of the hydro-mechanical material properties employed, the excavation and construction of an underground car park located in central London (Wood \& Perrin 1984a; Wood \& Perrin 1984b) was modelled, with the predicted response matching closely the measured field data. To highlight the contributions of each of the identified mechanisms - heat transfer and associated thermal expansion, differential thermal expansion of the pore fluid and soil particles, pore water pressure dissipation -, simplified analyses were carried out where one or more components of the coupled thermo-hydro-mechanical formulation were disregarded. The presented results focus on analysing in detail the magnitudes of structural forces, excess pore water pressures and wall and ground movements induced by the operation of the thermo-active retaining wall as a heat exchanger.

The following main conclusions can be drawn from the presented study:

- The modelling of a retaining wall using 2D plane strain analyses implies that the free expansion of the wall due to temperature changes (i.e. disregarding the restriction applied by the soil) includes a component of strain proportional to the Poisson's ratio of the material. This clearly differentiates this type of structure from thermo-active piles;

- The obtained results suggest that the behaviour of retaining walls subjected to temperature changes is highly transient in nature as a result of the high rates at which heat transfer and pore water pressure dissipation take place under plane strain assumptions;

- Even though simpler modelling approaches tend to be conservative in terms of structural forces (in the analysed cases all of the simpler analyses resulted in larger axial forces in the short term than the fully-coupled THM analysis), the same is not true for wall and ground movements in the long term, which are severely underestimated;

- In terms of structural forces, it was shown that axial forces and bending moments are highly influenced by the development of thermally-induced pore water pressures arising from the greater thermal expansion of the pore fluid when compared to that of the soil skeleton;

- While relatively low magnitudes of thermally-induced forces were predicted, it should be noted that this study assumed that pinned connections between the wall and internal structures were present. Other types of connection (e.g. full moment connection) are expected to further restrict the wall and result in increases of thermally-induced structural forces;

- The effects of temperature on horizontal wall displacements appear to be negligible. However, the calculated vertical wall and ground movements were shown to be significant, indicating the need to carry out adequate assessments during design in order to guarantee serviceability of the structure and evaluate any possible interaction with nearby structures.

In general, the obtained results demonstrate that fully coupled THM analysis should be employed for the design of thermo-active retaining walls, as simpler forms of analyses, ignoring selected aspects of the coupled THM behaviour of soil, fail to capture the full set of phenomena controlling soil-structure interaction.

\section{Acknowledgements}

The PhD programme of the first author is sponsored by the Department of Civil and Environmental Engineering, Imperial College London, through a Skempton Scholarship. 


\section{Appendix A. Mechanical material properties}

Table A. 1, Table A. 2, Table A. 3 and Table A. 4 summarise the linear and non-linear mechanical properties of the concrete structure and soil layers employed in all analyses, adopted from Gawecka et al. (2017).

\begin{tabular}{l|l|l} 
Material & $E[\mathrm{kPa}]$ & $\mu[--]$ \\
\hline Concrete & $30 \times 10^{6}$ & 0.3 \\
\hline Made Ground & $10 \times 10^{3}$ & 0.2 \\
\hline
\end{tabular}

Table A. 1: Linear elastic properties

\begin{tabular}{l|c|c|c} 
Material & $c^{\prime}[\mathrm{kPa}]$ & $\varphi^{\prime}\left[{ }^{\circ}\right]$ & $\psi^{\prime}\left[^{\circ}\right]$ \\
\hline Made Ground & 0.0 & 30.0 & 0.0 \\
\hline Terrace Gravel & 0.0 & 35.0 & 17.5 \\
\hline London Clay & 5.0 & 25.0 & 12.5 \\
\hline Lambeth Group Clay & 25.0 & 27.0 & 13.5 \\
\hline Thanet Sand & 0.0 & 40.0 & 20.0 \\
\hline
\end{tabular}

Table A. 2: Mohr-Coulomb strength properties

\begin{tabular}{l|c|c|c|c|c} 
Material & $G_{0}[\mathrm{kPa}]$ & $a[--]$ & $b[--]$ & $R_{G, \min }[\mathrm{kPa}]$ & $G_{\min }[\mathrm{kPa}]$ \\
\hline Terrace Gravel & 41939.61 & 0.000145 & 1.0 & 0.03511 & 3000 \\
\hline London Clay & 51743.55 & 0.000056 & 0.9 & 0.06450 & 2667 \\
\hline Lambeth Group Clay & 51924.52 & 0.000110 & 0.95 & 0.04662 & 2667 \\
\hline Thanet Sand & 65275.23 & 0.000046 & 0.85 & 0.02631 & 2000 \\
\hline
\end{tabular}

\begin{tabular}{l|c|c|c|c|c} 
Material & $K_{0}[\mathrm{kPa}]$ & $r[--]$ & $s[--]$ & $R_{K, \min }[\mathrm{kPa}]$ & $K_{\min }[\mathrm{kPa}]$ \\
\hline Terrace Gravel & 49843.08 & 0.000247 & 1.25 & 0.15440 & 3000 \\
\hline London Clay & 26692.73 & 0.000127 & 1.8 & 0.13275 & 5000 \\
\hline Lambeth Group Clay & 61331.71 & 0.000065 & 1.4 & 0.07589 & 5000 \\
\hline Thanet Sand & 29813.53 & 0.000155 & 1.1 & 0.27947 & 5000 \\
\hline
\end{tabular}

With the exception of Made Ground, the pre-yield behaviour of all the other soils is assumed to be reproduced by the non-linear small-strain stiffness model proposed by Taborda et al. (2016). According to this model, the tangent shear modulus, $G_{\text {tan }}$, is given by:

$$
G_{\text {tan }}=G_{\text {max }} \cdot\left[R_{G, \text { min }}+\frac{1-R_{G, \text { min }}}{1+\left(\frac{E_{d}}{a}\right)^{b}}\right] \geq G_{\text {min }}
$$

where $E_{d}$ is the second invariant of the strain tensor (see Equation A2), $G_{\min }$ is the minimum shear stiffness and $a, b$ and $R_{G, \min }$ are model parameters.

$$
E_{d}=\left(\frac{4}{6} \cdot\left[\left(\varepsilon_{x}-\varepsilon_{y}\right)^{2}+\left(\varepsilon_{y}-\varepsilon_{z}\right)^{2}+\left(\varepsilon_{z}-\varepsilon_{x}\right)^{2}\right]+\gamma_{x y}{ }^{2}+\gamma_{y z}{ }^{2}+\gamma_{x z}{ }^{2}\right)^{\frac{1}{2}}
$$

In Equation $\mathrm{A} 1$, the maximum shear stiffness, $G_{\max }$, is calculated using:

$$
G_{\text {max }}=G_{0} \cdot\left(\frac{p^{\prime}}{p_{\text {ref }}^{\prime}}\right)^{m_{G}}
$$


where $p^{\prime}$ is the mean effective stress, $p_{r e f}^{\prime}$ is a reference pressure (assumed to be equal to the atmospheric pressure, i.e. $101.3 \mathrm{kPa}$ ), while $G_{0}$ and $m_{G}$ are model parameters (in this paper, the latter is assumed to be 1.0 , i.e. the shear stiffness varies linearly with $p^{\prime}$ ).

Similarly, the tangent bulk modulus, $K_{\text {tan }}$, is given by:

$$
K_{\text {tan }}=K_{\text {max }} \cdot\left[R_{K, \text { min }}+\frac{1-R_{K, \text { min }}}{1+\left(\frac{\left|\varepsilon_{\text {vol }}\right|}{r}\right)^{s}}\right] \geq K_{\text {min }}
$$

where $\varepsilon_{v o l}$ is the volumetric strain (i.e. the first invariant of the strain tensor, see Equation A5), $K_{\min }$ is the minimum bulk modulus and $r, s$ and $R_{K, \min }$ are model parameters.

$$
\varepsilon_{\text {vol }}=\varepsilon_{x}+\varepsilon_{y}+\varepsilon_{z}
$$

In Equation $\mathrm{A} 4$, the maximum bulk modulus, $K_{\max }$, is calculated using:

$$
K_{\text {max }}=K_{0} \cdot\left(\frac{p^{\prime}}{p_{\text {ref }}^{\prime}}\right)^{m_{K}}
$$

where $K_{0}$ and $m_{K}$ are model parameters (as for the shear stiffness, the latter is assumed to be 1.0, i.e. the bulk modulus varies linearly with $p^{\prime}$ ).

\section{References}

Abuel-Naga, H. M., Bergado, D. T. \& Bouazza, A. (2007) Thermally induced volume change and excess pore water pressure of soft Bangkok clay. Engineering Geology, 89, 144-154.

Adam, D. \& Markiewicz, R. (2009) Energy from earth-coupled structures, foundations, tunnels and sewers. Géotechnique, 59, 229-236.

Amatya, B., Soga, K., Bourne-Webb, P. J., Amls, T. \& Laloui, L. (2012) Thermo-mechanical behaviour of energy piles. Geotechnique, 62.

Banks, D. (2012) An Introduction to Thermogeology: Ground Source Heating and Cooling. $2^{\text {nd }}$ Edition.Wiley-Blackwell, Chichester.

Bourne-Webb, P. J., Amatya, B., Soga, K., Amis, T., Davidson, C. \& Payne, P. (2009) Energy pile test at Lambeth College, London: geotechnical and thermodynamic aspects of pile response to heat cycles. Geotechnique, 59, 237-248.

Bourne-Webb, P. J., Soga, K. \& Amatya, B. (2013) A framework for understanding energy pile behaviour. Proceedings of the ICE - Geotechnical Engineering, 166, 170-177.

Bourne-Webb, P. J., Da Costa Gonçalves, R. A. \& Bodas Freitas, T. M. (2015) Retaining walls as heat exchangers: A numerical study. Geotechnical Engineering for Infrastructure and Development - Proceedings of the XVI European Conference on Soil Mechanics and Geotechnical Engineering, ECSMGE 2015, 5, 2499-2504.

Bourne-Webb, P. J., Bodas Freitas, T. M. \& Da Costa Gonçalves, R. A. (2016) Thermal and mechanical aspects of the response of embedded retaining walls used as shallow geothermal heat exchangers. Energy and Buildings, 125, 130-141.

Brandl, H. (2006) Energy foundations and other thermo-active ground structures. Géotechnique, 56 (2), 81-122.

Campanella, R. G. \& Mitchell, J. K. (1968) Influence of temperature variations on soil behaviour. ASCE Journal Soil Mechanics and Foundation Engineering Division, 4.

Cui, W. (2015) Development, Implementation And Application Of Thermo-Hydro-Mechanical Coupling For Soils In Finite Element Analysis. PhD Thesis, Imperial College London. 
Cui, W., Gawecka, K. A., Potts, D. M., Taborda, D. M. G., \& Zdravković, L. (2016a). Numerical analysis of coupled thermo-hydraulic problems in geotechnical engineering. Geomechanics for Energy and the Environment, 6, 22-34.

Cui, W., Gawecka, K. A., Taborda D. M. G., Potts, D. M., Zdravković, L. (2016b) Time-step constraints in transient coupled finite element analysis. International Journal for Numerical Methods in Engineering, 106(12), 953-971.

Cui, W., Potts, D. M., Zdravković, L., Gawecka, K. A., Taborda, D. M. G. (2018) An alternative coupled thermo-hydro-mechanical finite element formulation for fully saturated soils, Computers and Geotechnics, 94, 22-30.

Environment Agency (2016) Management of the London Basin Chalk Aquifer Status Report 2016, Environment Agency.

Gawecka, K. A., Taborda, D. M. G., Potts, D. M., Cui, W., Zdravković, L. \& Haji Kasri, M. (2017) Numerical modelling of thermo-active piles in London Clay. Proceedings of the Institution of Civil Engineers - Geotechnical Engineering, 1-19.

Hight, D. W., Higgins, K. G., Jardine, R. J., Potts, D. M., Pickles, A. R., De Moor, E. K. \& Nyirenda, Z. M. (1993) Predicted and measured tunnel distortions associated with construction of Waterloo International Terminal. In: Houlsby, G. T. \& Schofield, A. N. (eds.) Predictive soil mechanics. London: Thomas Telford.

Loveridge, F., Holmes, G., Powrie, W., \& Roberts, T. (2013). Thermal response testing through the Chalk aquifer in London, UK. Proceedings of the Institution of Civil Engineers - Geotechnical Engineering, 166(2), 197-210.

Potts, D. M. \& Zdravković, L. (1999) Finite element analysis in geotechnical engineering. theory. London, Thomas Telford.

Rui, Y. \& Yin, M. (2017) Thermo-hydro-mechanical coupling analysis of a thermo-active diaphragm wall. Canadian Geotechnical Journal. 55 (5), 720-735.

Schroeder, F. C., Potts, D. M. and Addenbrooke, T. I. (2004) The influence of pile group loading on existing tunnels. Géotechnique, 54 (6): 351-362.

Soga, K., Qi, H., Rui, Y. \& Nicholson, D. (2014) Some considerations for designing GSHP coupled geotechnical structures based on a case study. 7th International Congress on Environmental Geotechnics. Melbourne, Australia.

Sterpi, D., Coletto, A., \& Mauri, L. (2017). Investigation on the behaviour of a thermo-active diaphragm wall by thermo-mechanical analyses. Geomechanics for Energy and the Environment, 9, 1-20.

Sterpi, D., Angelotti, A., Habibzadeh-Bigdarvish, O., \& Jalili, D. (2018). Assessment of thermal behaviour of thermo-active diaphragm walls based on monitoring data. Journal of Rock Mechanics and Geotechnical Engineering, 10 (6), 1145-1153.

Taborda, D. M. G, Potts, D. M. \& Zdravković, L. (2016) On the assessment of energy dissipated through hysteresis in finite element analysis. Computers \& Geotechnics, 71, 180-194.

Wood, L. A. \& Perrin, A. J. (1984a) Observations of a strutted diaphragm wall in London clay: A preliminary assessment. Géotechnique, 34(4), 563-579.

Wood, L. A. \& Perrin, A. J.(1984b) Monitoring of a Deep Basement in London. International Conference on Case Histories in Geotechnical Engineering, 301-308

Xia, C., Sun, M., Zhang, G., Xiao, S. \& Zou, Y. (2012) Experimental study on geothermal heat exchangers buried in diaphragm walls. Energy and Buildings, 52, 50-55.

Zdravković, L., Potts, D. M. \& St John, H. D. (2005) Modelling of a 3D excavation in finite element analysis. Géotechnique, 55(7), 497-513. 